
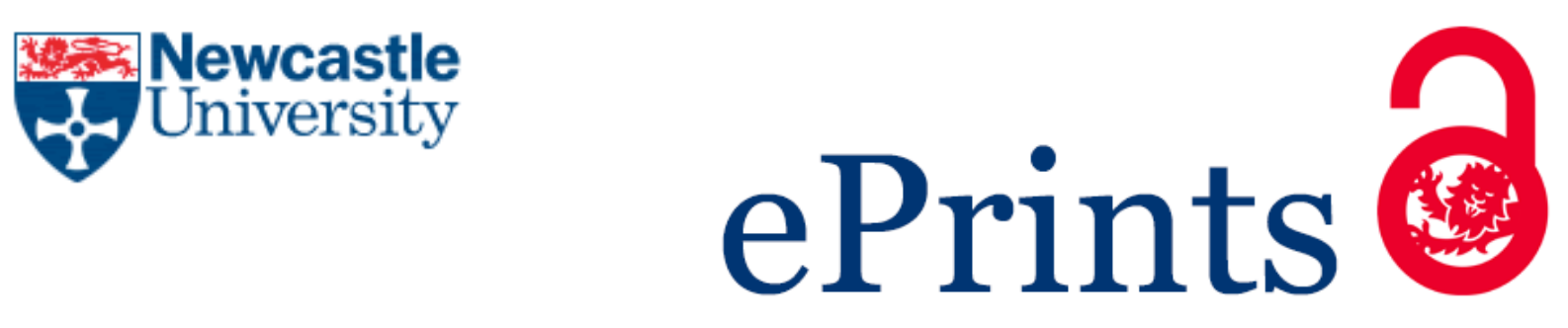

Cheng D, Wang S, Yang C, Mao ZS.

Numerical Simulation of Turbulent Flow and Mixing in Gas-Liquid-Liquid

Stirred Tanks.

Industrial \& Engineering Chemistry Research 2017

DOI: https://doi.org/10.1021/acs.iecr.7b01327

Copyright:

This document is the Accepted Manuscript version of a Published Work that appeared in final form in Industrial \& Engineering Chemistry Research, copyright (C) American Chemical Society after peer review and technical editing by the publisher. To access the final edited and published work see

https://doi.org/10.1021/acs.iecr.7b01327

DOI link to article:

https://doi.org/10.1021/acs.iecr.7b01327

Date deposited:

$02 / 06 / 2017$

Embargo release date:

02 June 2018 
Engineering Science

Elsevier Editorial System(tm) for Chemical

Manuscript Draft

Manuscript Number:

Title: Numerical Simulation of Turbulent Flow and Mixing in Gas-LiquidLiquid Stirred Tanks

Article Type: Research paper

Section/Category: Reaction Engineering, Kinetics and Catalysis

Keywords: turbulent flow; mixing; gas-liquid-liquid; turbulence model; computational fluid dynamics

Corresponding Author: Professor Chao Yang, Ph.D.

Corresponding Author's Institution: Chinese Academy of Sciences

First Author: Dang Cheng, Ph.D.

Order of Authors: Dang Cheng, Ph.D.; Steven Wang, Ph.D.; Chao Yang, Ph.D.

Abstract: The turbulent flows and macro-mixing processes in gas-liquidliquid flat-bottomed cylindrical stirred vessels agitated by a Rushton turbine have been numerically simulated based on the Eulerian multi-fluid approach using the RANS technique. Both the isotropic $k-\varepsilon$ model and anisotropic Reynolds stress model are used. The numerical models are validated by means of comparing simulated flow field of agitated immiscible liquid-liquid dispersions to the corresponding experimental data from literature. The predicted time traces of normalized concentration and values of mixing time in gas-liquid-liquid stirred tanks are compared to the experimentally measured ones as well. Both the $\mathrm{k}-\varepsilon$ model and the Reynolds stress model correspond reasonably well to the experimental data in both turbulent liquid-liquid and gas-liquid-liquid stirred tanks, and the anisotropic Reynolds stress model produces better results in terms of flow field, homogenization curve and mixing time than the $k-\varepsilon$ model. While the better accuracy of the Reynolds stress model comes at the cost of more computational time.

Suggested Reviewers: Vivek V. Ranade Ph.D.

Professor, School of Chemistry and Chemical Engineering, Queen's University Belfast, UK

V.Ranade@qub.ac.uk; ranade.ncl@gmail.com

Prof. Ranade is an expert on CFD modeling of hydrodynamics and mixing in multiphase stirred reactors.

Yundong Wang Ph.D.

Professor, Department of Chemical Engineering, Tsinghua University wangydemail.tsinghua.edu.cn

Prof. Yundong Wang is an expert on hydrodynamics and mixing in multiphase stirred reactors.

Jie Wu Ph.D.

Team Leader, Process Science and Engineering, CSIRO Process Science and Engineering, Australia 
Jie.Wulcsiro.au

Dr. Wu is an expert on multiphase stirred tanks and mixing, and he has industrial experience.

Milan Jahoda Ph.D.

Professor, Department of Chemical Engineering, Institute of Chemical Technology, Czech Republic

Milan.Jahodaevscht.cz

Prof. Jahoda is an expert on CFD modeling of mixing in stirred reactors.

Joelle Aubin Ph.D.

Professor, Laboratory of Chemical Engineering, University of Toulouse Joelle.Aubin@ensiacet.fr

Prof. Aubin is an expert in the field of hydrodynamics and mixing in single and multiphase stirred reactors.

Zheng-Hong Luo Ph.D.

Professor, Department of Chemical Engineering, Shanghai Jiao Tong University

luozhesjtu.edu.cn

Prof. Zheng-Hong Luo is an expert on hydrodynamics and transport in multiphase reactors.

Opposed Reviewers: 
Dr. Chao Yang

Professor of Chemical Engineering

Institute of Process Engineering,

Chinese Academy of Sciences

Beijing 100190, China

chaoyang@ipe.ac.cn

Dec. 30, 2016

\section{Dear Editor:}

Please find the enclosed manuscript entitled "Numerical Simulation of Turbulent Flow and Mixing in Gas-Liquid-Liquid Stirred Tanks" by Dang Cheng, Steven Wang and Chao Yang. We assure you that this manuscript is original and not submitted elsewhere for publication.

The manuscript is prepared using Microsoft Word in accordance with the author guidelines of Chemical Engineering Science. The file (Cheng2016.docx) according to the style of this Journal is attached. The manuscript consists of 46 pages of text (including two pages of collected table and figure captions), 8 tables and 12 illustrations.

We are grateful for your kind consideration on publication of our paper in Chemical Engineering Science and look forward to hearing from you about review reports at your early convenience.

Yours Sincerely,

Chao Yang 


\section{Short Introduction}

Gas-Liquid-liquid stirred tanks are extensively used but scarcely studied in chemical reaction engineering. The scientific design and scale-up/down of such reactors require a thorough understanding of the relevant hydrodynamics and mixing properties. Nevertheless, it is still a challenging problem to experimentally investigate the hydrodynamics and transport properties in such reactors due to their notoriously complex and inherently unsteady flow with intense multiphase interactions. In spite of its great importance, numerical simulations of hydrodynamics and mixing characteristics in gas-liquid-liquid three-phase stirred reactors have never been attempted before in the open literature.

In this paper, the turbulent flows and macro-mixing processes in gas-liquid-liquid flat-bottomed cylindrical stirred vessels agitated by a Rushton turbine have been numerically simulated based on the Eulerian multi-fluid approach using the RANS technique. Both the isotropic $k-\varepsilon$ model and the anisotropic Reynolds stress model are used. The inert tracer macro-mixing processes in the continuous phase of the threephase stirred reactor are measured by using the conductivity method in order to validate the numerical models. The numerical models are first validated by means of comparing simulated flow field of agitated immiscible liquid-liquid dispersions to the corresponding experimental data from literature. Then, the predicted time traces of the normalized concentration and the values of mixing time from gas-liquid-liquid stirred tanks are compared to the experimentally measured ones as well. It is found that the $k$ $\varepsilon$ model and the Reynolds stress model correspond reasonably well to the experimental data in both turbulent liquid-liquid and gas-liquid-liquid stirred tanks, and the anisotropic Reynolds stress model produces better results in terms of flow field, homogenization curve and mixing time than the $k-\varepsilon$ model. 
Highlights

- The flow and macro-mixing in gas-liquid-liquid stirred tanks are simulated.

- Both the $k-\varepsilon$ model and the Reynolds stress model are used.

- The numerical predictions are validated against experimental data.

- The Reynolds stress model produces better results than the $k-\varepsilon$ model.

- The Reynolds stress model is much more computationally expensive. 


\title{
Numerical Simulation of Turbulent Flow and Mixing in
}

\section{Gas-Liquid-Liquid Stirred Tanks}

\author{
Dang Cheng ${ }^{1,2,3}$, Steven Wang ${ }^{4}$, Chao Yang ${ }^{1 *}$ \\ 1. Key Laboratory of Green Process and Engineering, Institute of Process \\ Engineering, Chinese Academy of Sciences, Beijing 100190, China \\ 2. Department of Chemical Engineering and Chemistry, Eindhoven University of \\ Technology, The Netherlands \\ 3. LCPP-CNRS, C2P2-UMR 5265, CPE Lyon, University Claude-Bernard Lyon 1, \\ Villeurbanne 69616, France \\ 4. School of Chemical Engineering and Advanced Materials, Newcastle University, \\ $N E 17 R U, U K$
}

\begin{abstract}
The turbulent flows and macro-mixing processes in gas-liquid-liquid flat-bottomed cylindrical stirred vessels agitated by a Rushton turbine have been numerically simulated based on the Eulerian multi-fluid approach using the RANS technique. Both the isotropic $k-\varepsilon$ model and anisotropic Reynolds stress model are used. The numerical models are validated by means of comparing simulated flow field of agitated immiscible liquid-liquid dispersions to the corresponding experimental data from literature. The predicted time traces of normalized concentration and values of mixing time in gas-liquid-liquid stirred tanks are compared to the experimentally measured ones as well. Both the $k-\varepsilon$ model and the Reynolds stress model correspond reasonably well to the experimental data in both turbulent liquid-liquid and gas-liquid-liquid stirred tanks, and the anisotropic Reynolds stress model produces better results in terms of flow field, homogenization curve and mixing time than the

* To whom correspondence should be addressed. Tel.: +86-10-62554558. Fax: +86-10-82544928. E-mail address: chaoyang@ipe.ac.cn.
\end{abstract}


$k-\varepsilon$ model. While the better accuracy of the Reynolds stress model comes at the cost of more computational time.

Keywords: turbulent flow; mixing; gas-liquid-liquid; turbulence model; computational fluid dynamics

\section{Introduction}

Mechanically agitated vessels involving gas-liquid-liquid three phase dispersions are extensively used in chemical and biochemical industries, such as hydroformylation, hydrogenation and microorganism fermentation, etc. In some applications, the chemical reaction takes place between the three phases. In some of other cases, the chemical reaction occurs between the gas phase and the dispersed immiscible organic phase in the inertial continuous phase. The mixing and simultaneous dispersion of gas and oil droplets provided by the agitator play central roles in determining the performance of such reactors, which significantly affect the quality of product, yield and economy of the processes. A waste of processing time and raw materials and/or the formation of by-products may be resulted due to insufficient or excessive mixing (Yeoh et al., 2004). Despite their widespread applications, the gas-liquid-liquid stirred reactors have been rarely studied in the open literature. Only a few studies have been carried out to understand the critical impeller speed for complete oil dispersion (Kamil et al., 2001), gas absorption rate into the continuous phase (Dumont and Delmas, 2003; Linek and Benes, 1976; Van Ede et al., 1995), the influence of a second dispersed oil phase on gas-water interfacial area (Das

et al., 1985), the effect of agitation on macro-kinetics of biphasic catalyzed hydroformylation (Yang et al., 2002a, 2002b) and the macro-mixing of the continuous phase (Cheng et al., 2012). 
The scientific design and scale-up/down of gas-liquid-liquid stirred reactors require a thorough understanding of the hydrodynamics (e.g., velocity fields and phase holdup distributions) and mixing properties in such highly turbulent multiphase systems. Nevertheless, it is still a challenging problem to experimentally investigate the hydrodynamics and transport properties in such reactors due to their notoriously complex and inherently unsteady flows with intense multiphase interactions. The industrially relevant gas-liquid-liquid dispersions are usually non-transparent with high values of oil and gas holdups, and the droplets/bubbles severely scatter light, which make their fluid dynamic characteristics are extremely difficult to be measured by means of the popular optical measurements such as particle image velocimetry (PIV) or laser Doppler anemometry (LDA) techniques. While, the prohibitive cost severely restricts the widespread accessibility of the 3D electrical resistance, $\mathrm{x}$-ray/computed tomography and radioactive particle tracking techniques.

With the rapid advancement of computer performance, fortunately, the numerical simulation approach provides a highly useful alternative, which is capable of quantitatively revealing global as well as detailed localized information about the flow and mixing characteristics by numerically solving fundamental transport equations. Though various methods are available to simulate the turbulent flow in stirred tanks, the computationally efficient Reynolds-averaged Navier-Stokes (RANS) approach coupled with a suitable turbulence model, which has been widely shown to produce reasonably acceptable results, is possibly the most promising tool for industrial applications.

Much effort has been made to simulate the turbulent flows and mixing properties in single phase (Grenville and Nienow, 2004; Nere et al., 2003) and two-phase stirred reactors, e.g., gas-liquid (Sun et al., 2006; Wang et al., 2006b), solid-liquid (Feng et 
al., 2012; Shan et al., 2008) and liquid-liquid (Cheng et al., 2013; Wang and Mao, 2005) systems. Whereas, numerical modeling of the flow and mixing characteristics in three-phase stirred reactors is rarely seen in the open literature.

Based on the Eulerian multi-fluid approach coupled with the standard $k-\varepsilon$ model, Murthy et al. (2007, 2008) have undertaken simulations for obtaining the critical impeller speed for solid suspension over a range of solid loadings $(2 \sim 15 \mathrm{wt} . \%)$, for different impeller designs, solid particles sizes and various gas velocities in gas-liquid-solid stirred reactors. They concluded that the critical impeller speeds for solid suspension obtained from CFD model could match well with the corresponding experimental data. Further work has been carried out by Panneerselvam et al. (2008a, 2008b) to predict the critical impeller speed for high density solid particles with solid concentrations varying from $10 \mathrm{wt} . \%$ to $30 \mathrm{wt} . \%$ by using a multi-fluid approach together with the standard $k-\varepsilon$ model. Wang et al. (2006a) simulated the liquid-liquid-solid three-phase stirred tanks by means of an Eulerian-Eulerian three-fluid approach along with the $k-\varepsilon$ turbulence model, and they measured the holdup distribution of the dispersed phases by using a sample withdrawal method. A reasonable agreement was reached between the predicted holdup distributions of solid/oil phases and the corresponding measured values. Wang et al. (2010) numerically investigated the liquid-solid-solid dispersion characteristics in a lab-scale stirred vessel using an Eulerian multi-fluid model together with the RNG $k-\varepsilon$ turbulence model.

To our best knowledge, numerical simulations of hydrodynamics and macro-mixing characteristics in gas-liquid-liquid three-phase stirred reactors have not been reported in the open literature. Therefore, this work attempts to fill this void. Furthermore, how the RANS approach coupled with different turbulence models 
(isotropic \& anisotropic) performs in the description of highly turbulent gas-liquid-liquid flows in stirred reactors is a significant but still unresolved problem. Accordingly, the comparative studies between the typical isotropic $k$ - $\varepsilon$ model and typical anisotropic Reynolds stress model (RSM) are made as well. As the macro-mixing information including mixing time values and homogenization curves are very useful indicators for the underlying fluid dynamics, so the inert tracer macro-mixing processes in the continuous phase of the three-phase stirred reactor are measured by using the conductivity method in order to validate the numerical models.

\section{Experimental}

\subsection{Experimental setup}

The experimental gas-liquid-liquid system involves air, water and immiscible kerosene oil. Air and kerosene were used as the dispersed phases and the tap water as the continuous phase. The experimental setup is sketched in Figure 1. The flat-bottomed cylindrical stirred vessel had a diameter of $T=0.24 \mathrm{~m}$ and the liquid height was set at $H=T$. Four vertical baffles of width $T / 10 \mathrm{~m}$ were mounted equally-spaced to the vessel wall. The sparger was installed directly under the impeller. A standard Rushton turbine with diameter of $D=T / 3$ was employed. 


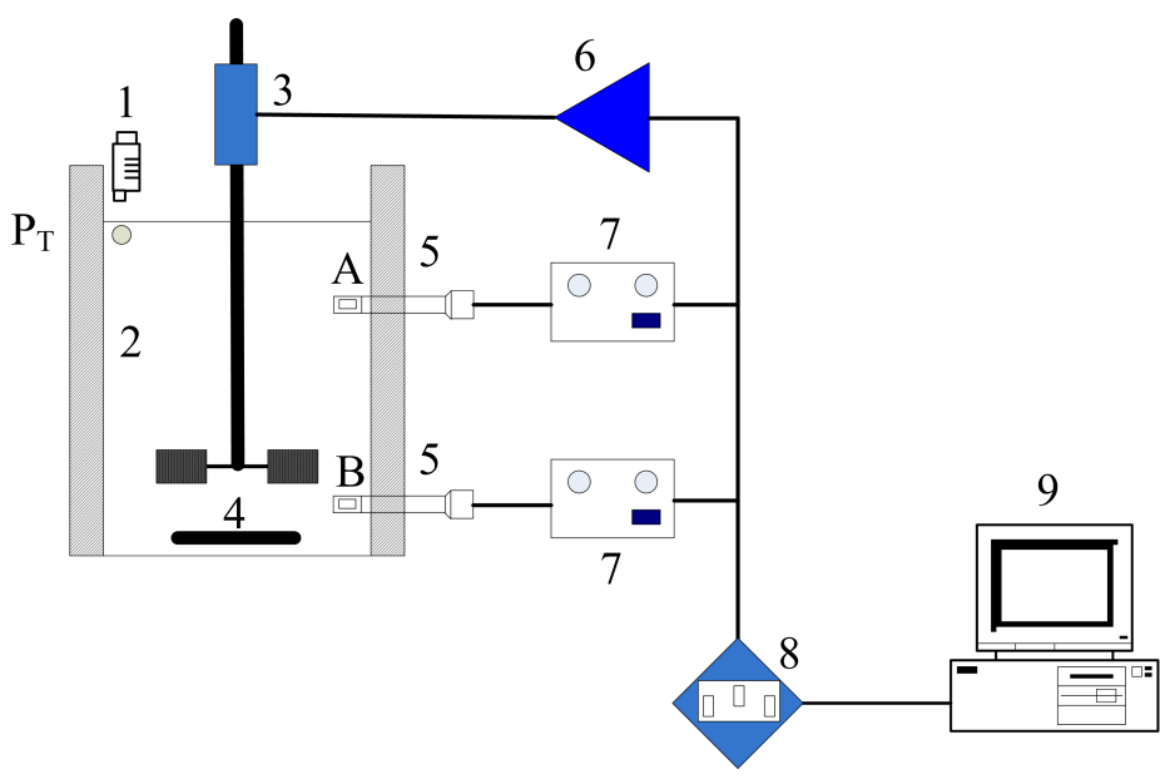

Figure 1. Experimental setup

1. injector, 2.stirred tank, 3. rotary torque transducer, 4.sparger, 5. conductivity electrode, 6. amplifier, 7. conductometer, 8.data collector, 9.computer.

Probe A: $115 \mathrm{~mm}$ from shaft axis and $192 \mathrm{~mm}$ from bottom;

Probe B: $115 \mathrm{~mm}$ from shaft axis and $30 \mathrm{~mm}$ from bottom.

\subsection{Measurement method}

The measurements were conducted in the range of relatively low oil phase holdups and gas flow rates. The reasons were that high gas flow rates $(>1.4 \mathrm{~L} / \mathrm{min})$ made it difficult to completely disperse the oil phase, and both high gas flow rates and high oil holdups introduced much noise to the conductivity measurement.

The mixing time was measured by using the conductivity method (Cheng et al., 2012). $10 \mathrm{~mL} \mathrm{NaCl}$ solution $(250 \mathrm{~g} / \mathrm{L})$ is instantly injected into the reactor at point $\mathrm{P}_{\mathrm{T}}$ (at the liquid surface and $0.115 \mathrm{~m}$ from the shaft axis) after the agitated dispersion reached stable state (approximate one hour of agitation). Two conductivity probes (Probe A and Probe B) with sampling frequency of $100 \mathrm{~Hz}$ were used to monitor the real time voltage signal, which is linearly related $\mathrm{NaCl}$ concentration. The mixing 
time is defined as the duration from addition of tracer to the instant when the concentration arrives within $\pm 5 \%$ of its final value.

\section{Mathematical model}

The mathematical equations are formulated based on the Eulerian multi-fluid approach. Water, oil and gas phases are assumed as continua coexisting, penetrating and interacting with each other everywhere in the reactor. As a consequence, the mass and momentum transport equations are solved for each phase separately, and coupled with each other through interphase interaction terms. The mass and momentum transport equations for phase $\varphi$ are represented as

$$
\begin{gathered}
\frac{\partial}{\partial t}\left(\rho_{\varphi} \alpha_{\varphi}\right)+\nabla \cdot\left(\rho_{\varphi} \alpha_{\varphi} \mathbf{u}_{\varphi}\right)=0 \\
\frac{\partial\left(\rho_{\varphi} \alpha_{\varphi} \mathbf{u}_{\varphi}\right)}{\partial t}+\nabla \cdot\left(\rho_{\varphi} \alpha_{\varphi} \mathbf{u}_{\varphi} \mathbf{u}_{\varphi}\right)=-\alpha_{\varphi} \nabla p+\nabla \cdot\left(\mu_{\varphi, \text { eff }} \alpha_{\varphi}\left(\nabla \mathbf{u}_{\varphi}+\left(\nabla \mathbf{u}_{\varphi}\right)^{T}\right)\right)+\rho_{\varphi} \alpha_{\varphi} g+\mathbf{F}_{\varphi}
\end{gathered}
$$

where $\varphi$ is the phase index, which can be "c" for the continuous phase, "o" for the oil phase and " $\mathrm{g}$ " for the gas phase.

The Reynolds averaged governing equations (see Wang and Mao, 2005; Wang et al., 2006a) are coupled with two typical turbulence models in this work. The turbulence models are usually grouped into two main categories, i.e., isotropic and anisotropic models. The typical isotropic model is the $k-\varepsilon$ model, which is robust and extensively used in the literature. The Reynolds stress model (RSM) is a typical anisotropic model, which is computationally expensive and less used in the literature.

\section{$3.1 k-\varepsilon$ turbulence model}

The presence of Reynolds stress tensor requires closure modeling. In this work, 
the turbulence closure equations are solved in the primary phase, namely, the continuous phase, while the Hinze-Tchen's theory (Hinze, 1959) is used to account for the correlation between phases. As the $k-\varepsilon$ model is based on the isotropic hypothesis of eddy viscosity, so the Reynolds stresses tensor is approximated with

$$
-\rho_{\mathrm{c}} \overline{u_{\mathrm{c}, i}^{\prime} u_{\mathrm{c}, j}^{\prime}}=\mu_{\mathrm{c}, t}\left(\frac{\partial u_{\mathrm{c}, j}}{\partial x_{i}}+\frac{\partial u_{\mathrm{c}, i}}{\partial x_{j}}\right)-\frac{2}{3} k \rho_{\mathrm{c}} \delta_{i j}
$$

where $\mu_{\mathrm{c}, \mathrm{t}}=\rho_{\mathrm{c}} C_{\mu} \frac{k^{2}}{\varepsilon}$ is the eddy viscosity of the continuous phase. The turbulence kinetic energy $k$ and the energy dissipation rate $\varepsilon$ are solved from the corresponding transport equations:

$$
\begin{aligned}
& \frac{\partial}{\partial t}\left(\rho_{\mathrm{c}} \alpha_{\mathrm{c}} k\right)+\frac{\partial}{\partial x_{i}}\left(\rho_{\mathrm{c}} \alpha_{\mathrm{c}} u_{\mathrm{c}, i} k\right)=\frac{\partial}{\partial x_{i}}\left(\alpha_{\mathrm{c}} \frac{\mu_{\mathrm{c}, \mathrm{t}}}{\sigma_{\mathrm{k}}} \frac{\partial k}{\partial x_{i}}\right)+S_{\mathrm{k}} \\
& \frac{\partial}{\partial t}\left(\rho_{\mathrm{c}} \alpha_{\mathrm{c}} \varepsilon\right)+\frac{\partial}{\partial x_{i}}\left(\rho_{\mathrm{c}} \alpha_{\mathrm{c}} u_{\mathrm{c}, i} \varepsilon\right)=\frac{\partial}{\partial x_{i}}\left(\alpha_{\mathrm{c}} \frac{\mu_{\mathrm{c}, \mathrm{t}}}{\sigma_{\varepsilon}} \frac{\partial \varepsilon}{\partial x_{i}}\right)+S_{\varepsilon}
\end{aligned}
$$

where

$$
\begin{gathered}
S_{\mathrm{k}}=\alpha_{\mathrm{c}}\left[\left(G+G_{\mathrm{e}}\right)-\rho_{\mathrm{c}} \varepsilon\right] \\
S_{\varepsilon}=\alpha_{\mathrm{c}} \frac{\varepsilon}{k}\left[C_{1}\left(G+G_{\mathrm{e}}\right)-C_{2} \rho_{\mathrm{c}} \varepsilon\right]
\end{gathered}
$$

The model parameters recommended by Launder and Spalding (Launder and Spalding, 1974) is adopted: $\sigma_{\mathrm{k}}=1.0, \sigma_{\varepsilon}=1.3, C_{1}=1.44, C_{2}=1.92$ and $C_{\mu}=0.09$. The turbulent kinetic energy production term $\mathrm{G}$ is given by

$$
G=-\rho_{\mathrm{c}} \overline{u_{\mathrm{c}, i}^{\prime} u_{\mathrm{c}, j}^{\prime}} \frac{\partial u_{\mathrm{c}, i}}{\partial x_{\mathrm{j}}}
$$

The effect of the dispersed phases on the continuous phase turbulence is accounted for by an extra production term $G_{\mathrm{e}}$. Kataoka et al.(1992) suggested that the value of $G_{\mathrm{e}}$ can be estimated by 


$$
G_{\mathrm{e}}=C_{\mathrm{b}}\left|\mathbf{F}_{\mathrm{drag}}\right| \sqrt{\sum\left(u_{\mathrm{d}, i}-u_{\mathrm{c}, i}\right)^{2}}
$$

where $C_{\mathrm{b}}=0.02$ is an empirical parameter, and subscript $d$ represents the two dispersed phases.

The drawback of the $k-\varepsilon$ model is that the anisotropy can't be well accounted for as the turbulence is represented by $k$ and $\varepsilon$ (Hanjalić, 1994; Launder, 1990; Reynolds, 1987). Besides, the eddy viscosity model does not take into account the rotation and streamline curvature effects.

\subsection{Reynolds stress model}

In the Reynolds stress model (RSM), the transport of the full Reynolds stress tensor is modeled. The transport equation for the Reynolds stress is (Launder et al., 1975; Launder and Spalding, 1972)

$$
\begin{aligned}
& \frac{\partial \alpha_{\mathrm{c}} \rho_{\mathrm{c}} \overline{u_{i}^{\prime} u_{j}^{\prime}}}{\partial t}+\underbrace{\frac{\partial \alpha_{\mathrm{c}} \rho_{\mathrm{c}} u_{\mathrm{c}, k} \overline{u_{i}^{\prime} u_{j}^{\prime}}}{\partial x_{k}}}_{c_{i j}}=\underbrace{-\alpha_{\mathrm{c}} \rho_{\mathrm{c}}\left(\overline{u_{i}^{\prime} u_{k}^{\prime}} \frac{\partial u_{\mathrm{c}, j}}{\partial x_{k}}+\overline{u_{j}^{\prime} u_{k}^{\prime}} \frac{\partial u_{\mathrm{c}, i}}{\partial x_{k}}\right)}_{P_{i j}}-\underbrace{\frac{\partial}{\partial x_{k}}\left[\alpha_{\mathrm{c}} \rho_{\mathrm{c}} \overline{u_{i}^{\prime} \bar{u}_{j}^{\prime} u_{k}^{\prime}}+\alpha_{\mathrm{c}} \overline{p^{\prime}\left(\overline{u_{i}^{\prime}} \delta_{j k}+u_{j}^{\prime} \delta_{i k}\right)}\right]}_{D_{T, i j}} \\
& +\underbrace{\frac{\partial}{\partial x_{k}}\left(\alpha_{\mathrm{c}} \mu_{\mathrm{c}} \frac{\partial \overline{u_{i}^{\prime} u_{j}^{\prime}}}{\partial x_{k}}\right)}_{D_{L, i j}}-\underbrace{2 \alpha_{\mathrm{c}} \rho_{\mathrm{c}} \mu_{\mathrm{c}} \overline{\frac{\partial u_{i}^{\prime}}{\partial x_{k}} \frac{\partial u_{j}^{\prime}}{\partial x_{k}}}}_{\varepsilon_{i j}}+\underbrace{\alpha_{\mathrm{c}} \overline{p^{\prime}\left(\frac{\partial u_{i}^{\prime}}{\partial x_{j}}+\frac{\partial u_{j}^{\prime}}{\partial x_{i}}\right)}}_{\phi_{i j}}-\underbrace{2 \alpha_{\mathrm{c}} \rho_{\mathrm{c}} \Omega_{k}\left(\overline{u_{j}^{\prime} u_{m}^{\prime}} \varepsilon_{i k m}+\overline{u_{i}^{\prime} u_{m}^{\prime}} \varepsilon_{j k m}\right)}_{F_{i j}}
\end{aligned}
$$

where $P_{i j}$ is the production term, $D_{T, i j}$ is the turbulent diffusion term, $D_{L, i j}$ is the molecular diffusion term, $\varepsilon_{i j}$ is the dissipation term, $\phi_{i j}$ is the pressure-strain term and $F_{i j}$ is the production by system rotation.

The three terms $D_{T, i j}, \phi_{i j}$ and $\varepsilon_{i j}$ need to be modeled in order to close the equations. The $D_{T, i j}$ is modeled by Daly and Harlow (1970) using the generalized gradient diffusion hypothesis as 


$$
D_{T, i j}=c_{s} \frac{\partial}{\partial x_{k}}\left(\rho_{\mathrm{c}} \frac{k}{\varepsilon} \overline{u_{k}^{\prime} u_{l}^{\prime}} \frac{\partial \overline{u_{i}^{\prime} u_{j}^{\prime}}}{\partial x_{l}}\right)
$$

Eq. (11) was used in the original implementation in OpenFOAM. However, this equation leads to numerical instabilities, so a simplified closure suggested by Fluent (2011) is used in this work:

$$
D_{T, i j}=\frac{\partial}{\partial x_{k}}\left(\frac{\mu_{\mathrm{c}, \mathrm{t}}}{\sigma_{\mathrm{k}, \mathrm{RSM}}} \frac{\partial \overline{u_{i}^{\prime} u_{j}^{\prime}}}{\partial x_{k}}\right)
$$

where $\sigma_{\mathrm{k}, \mathrm{RSM}}=0.82$ (Lien and Leschziner, 1994). The dissipation term is approximated by

$$
\varepsilon_{i j}=\frac{2}{3} \delta_{i j} \rho_{\mathrm{m}} \varepsilon
$$

where $\varepsilon$ is obtained by solving its transport equation.

The pressure-strain term $\phi_{i j}$ is usually modeled by means of decomposing it into three components (Launder et al., 1975):

$$
\phi_{i j}=\phi_{i j, 1}+\phi_{i j, 2}+\phi_{i j, w}
$$

where $\phi_{i j, 1}$ is the slow pressure-strain term (also called return-to-isotropy term), $\phi_{i j, 2}$ is the rapid pressure-strain term and $\phi_{i j, w}$ is the wall reflection term. The three terms are modeled as

$$
\begin{gathered}
\phi_{i j, 1}=-C_{1} \alpha_{\mathrm{c}} \rho_{\mathrm{c}} \frac{\varepsilon}{k}\left(\overline{u_{i}^{\prime} u_{j}^{\prime}}-\frac{2}{3} k \delta_{i j}\right) \\
\phi_{i j, 2}=-C_{2}\left(\left(P_{i j}+F_{i j}-C_{i j}\right)-\frac{2}{3} \delta_{i j}(P-C)\right)
\end{gathered}
$$

where $P_{i j}, F_{i j}$ and $C_{i j}$ are defined in Eq. (10), $P=0.5 P_{k k}$ and $C=0.5 C_{k k}$. 


$$
\begin{aligned}
& \phi_{i j, w}=C_{1}^{\prime} \frac{\varepsilon}{k}\left[\overline{\overline{u_{k}^{\prime} u_{m}^{\prime}}} n_{k} n_{m} \delta_{i j}-\frac{3}{2} \overline{u_{i}^{\prime} u_{k}^{\prime}} n_{j} n_{k}-\frac{3}{2} \overline{u_{j}^{\prime} u_{k}^{\prime}} n_{i} n_{k}\right] \frac{C_{l} k^{1.5}}{\varepsilon d_{w}} \\
& +C_{2}^{\prime}\left[\phi_{k m, 2} n_{k} n_{m} \delta_{i j}-\frac{3}{2} \phi_{i k, 2} n_{j} n_{k}-\frac{3}{2} \phi_{j k, 2} n_{i} n_{k}\right] \frac{C_{l} k^{1.5}}{\varepsilon d_{w}}
\end{aligned}
$$

where $n_{k}$ is the $x_{k}$ component of the unit normal to the wall, $d_{\mathrm{w}}$ is the normal distance to the wall, and $C_{l}=\frac{C_{\mu}^{3 / 4}}{\kappa}$ with $\kappa=0.42$ is the von Karman constant.

The turbulent energy is calculated from

$$
k=\frac{\overline{u_{i}^{\prime} u_{i}^{\prime}}}{2}
$$

The transport equation for the dissipation rate is (Launder et al., 1975)

$$
\frac{\partial}{\partial t}\left(\alpha_{\mathrm{c}} \rho_{\mathrm{c}} \varepsilon\right)+\frac{\partial}{\partial x_{i}}\left(\alpha_{\mathrm{c}} \rho_{\mathrm{c}} u_{\mathrm{c}, i} \varepsilon\right)=\frac{\partial}{\partial x_{j}}\left(\left(\mu_{\mathrm{c}}+\frac{\mu_{\mathrm{c}, \mathrm{t}}}{\sigma_{\varepsilon}}\right) \frac{\partial \varepsilon}{\partial x_{j}}\right)+0.5 C_{\varepsilon 1} P_{i i} \frac{\varepsilon}{k}-C_{\varepsilon 2} \alpha_{\mathrm{c}} \rho_{\mathrm{c}} \frac{\varepsilon^{2}}{k}
$$

Modeling of the interaction between the continuous phase and dispersed phase turbulence is still a challenge for turbulent three-phase systems, though there were some attempts to formulate the dispersed RSM for two-phase systems by incorporating two-way coupling source terms into Eq.(10) (Beishuizen et al., 2007; Cokljat et al., 2006; Simonin and Viollet, 1990). While, instead of constructing two-way coupling source terms into Eq. (10), Sato and Sekoguchi (1975) proposed a modified formulation for the continuous phase eddy viscosity:

$$
\mu_{\mathrm{c}, \mathrm{t}}=C_{\mu} \rho_{\mathrm{c}} \frac{k^{2}}{\varepsilon}+\sum 0.6 \rho_{\mathrm{c}} \alpha_{\mathrm{d}} d_{\mathrm{d}}\left|\mathbf{u}_{\mathrm{d}}-\mathbf{u}_{\mathrm{c}}\right|
$$

Recently, Nygren (2014) has shown that the two-way coupling model by Sato and Sekoguchi gave indistinguishable results from those by Simonin and Viollet model (Simonin and Viollet, 1990). Therefore, Eq. (20) is adopted in order to make the two-way coupling formulation more tractable in this work. 
The model constants used in RSM are summarized in Table 1.

Table 1. RSM model constants.

\begin{tabular}{llllllllllll}
\hline$C_{\mu}$ & $\kappa$ & $C_{1}$ & $C_{2}$ & $C_{\varepsilon 1}$ & $C_{\varepsilon 2}$ & $C_{1}^{\prime}$ & $C_{2}^{\prime}$ & $C_{\mathrm{s}}$ & $C_{\varepsilon}$ & $\sigma_{\varepsilon}$ & $\sigma_{\mathrm{R}}$ \\
\hline 0.09 & 0.42 & 1.8 & 0.6 & 1.44 & 1.92 & 0.5 & 0.3 & 0.25 & 0.15 & 1.3 & 0.81967 \\
\hline
\end{tabular}

The advantage of the RSM is that anisotropy can be accounted for and the relationship between the mean rate of strain and the stress is not assumed to be linear.

\subsection{Interphase interaction}

The interphase interaction term represents momentum exchange between phases, which mainly comprises the drag force, Basset force, lift force and virtual mass force (Ranade, 2002). Only the drag force is considered in the interphase interaction term since other mechanisms were shown to be of much less significance in the liquid-liquid, gas-liquid, solid-liquid and gas-liquid-solid stirred tanks (Kasat et al., 2008; Khopkar et al., 2005; Murthy et al., 2007; Wang and Mao, 2005; Wang et al., 2006a; Wang et al., 2006b). The drag force between the dispersed oil phase and the continuous phase is expressed as

$$
\mathbf{F}_{\text {drag, co }}=\frac{3 C_{\mathrm{D}, \mathrm{co}} \rho_{\mathrm{c}} \alpha_{\mathrm{o}}\left|\mathbf{u}_{\mathrm{o}}-\mathbf{u}_{\mathrm{c}}\right|\left(\mathbf{u}_{\mathrm{o}}-\mathbf{u}_{\mathrm{c}}\right)}{4 d_{\mathrm{o}}}
$$

where Barnea and Mizrahi's drag model (Barnea and Mizrahi, 1975) is adopted as it takes into account both the droplet deformation and wall effect:

$$
C_{\mathrm{D}, \mathrm{co}}=\left(1+\alpha_{\mathrm{o}}^{\frac{1}{3}}\right)\left(0.63+\frac{4.8}{\sqrt{R e_{\mathrm{o}}}}\right)^{2}
$$


where $\quad R e_{\mathrm{o}}=\frac{d_{\mathrm{o}}\left|\mathbf{u}_{\mathrm{o}}-\mathbf{u}_{\mathrm{c}}\right| \rho_{\mathrm{c}}}{\mu_{\mathrm{m}, \mathrm{co}}} \quad, \quad \mu_{\mathrm{m}, \mathrm{co}}=\mu_{\mathrm{c}} K_{\mathrm{b}} \frac{\frac{2}{3} K_{\mathrm{b}}+\frac{\mu_{\mathrm{o}}}{\mu_{\mathrm{c}}}}{K_{\mathrm{b}}+\frac{\mu_{\mathrm{o}}}{\mu_{\mathrm{c}}}} \quad, \quad K_{\mathrm{a}}=\frac{\mu_{\mathrm{c}}+2.5 \mu_{\mathrm{o}}}{2.5 \mu_{\mathrm{c}}+2.5 \mu_{\mathrm{o}}} \quad$, $K_{\mathrm{b}}=\exp \left(\frac{5 \alpha_{\mathrm{o}} K_{a}}{3\left(1-\alpha_{\mathrm{o}}\right)}\right)$

The drag force between the dispersed gas phase and the continuous phase is expressed as

$$
\mathbf{F}_{\text {drag, } \mathrm{cg}}=\frac{3 C_{\mathrm{D}, \mathrm{cg}} \rho_{\mathrm{c}} \alpha_{\mathrm{g}}\left|\mathbf{u}_{\mathrm{g}}-\mathbf{u}_{\mathrm{c}}\right|\left(\mathbf{u}_{\mathrm{g}}-\mathbf{u}_{\mathrm{c}}\right)}{4 d_{\mathrm{b}}}
$$

Lane et al. (2000) investigated the influence of turbulence on the drag coefficient by means of comparing simulated gas holdup distributions to the corresponding experimental data, and they suggested using the correlation proposed by Brucato et al. (1998) with a modified turbulence correction factor. So, the drag between gas-water pair is represented by (Khopkar et al., 2005; Zhang et al., 2008)

$$
\begin{gathered}
\frac{C_{\mathrm{D}, \mathrm{cg}}-C_{\mathrm{D} 0}}{C_{\mathrm{D} 0}}=6.5 \times 10^{-6}\left(\frac{d_{\mathrm{b}}}{\lambda}\right)^{3} \\
C_{\mathrm{D} 0}=\max \left\{\frac{2.667 E o}{E o+4}, \frac{24}{R e_{\mathrm{b}}}\left(1+0.15 R e_{\mathrm{b}}^{0.687}\right)\right\}
\end{gathered}
$$

where $E o=\frac{g\left(\rho_{\mathrm{c}}-\rho_{\mathrm{g}}\right) d_{\mathrm{b}}{ }^{2}}{\sigma}, \quad \operatorname{Re}_{\mathrm{b}}=\frac{d_{\mathrm{b}}\left|\mathbf{u}_{\mathrm{g}}-\mathbf{u}_{\mathrm{c}}\right| \rho_{\mathrm{c}}}{\mu_{\mathrm{c}}}, \lambda$ is the Kolmogorov length scale.

The droplet size and bubble size distributions in gas-liquid-liquid stirred vessels are a function of various variables, e.g., oil holdup, gas flow rate, material properties, agitation speed and vessel geometry, etc. Ideally, to account for the droplet size and bubble size distributions, the numerical model should be coupled with the corresponding population balance equations. Nevertheless, the available knowledge 
and information for the present experimental stirred vessel is unfortunately far not adequate to model the coalescence and break-up kernels and obtain the values of the relevant parameters appearing in such kernels. In addition, there still exists a considerable uncertainty in the estimation of interphase drags on oil droplets and gas bubbles in the simultaneous presence of both other bubbles and droplets. Last but not least, the goal of this work is to simulate the main mean flow and macro-mixing characteristics in gas-liquid-liquid three-phase stirred vessels and examine how different turbulence models perform in such intricate systems. Therefore, as an attempt to numerically simulate such complex gas-liquid-liquid stirred vessels and also take into account the above mentioned issues in the meantime, we use classic correlations to estimate the prevailing droplet size and bubble size in our numerical models. This approach is practically feasible and can achieve an affordable computing time.

The well-developed correlation is employed to calculate the droplet size. $d_{\mathrm{o}}$ is widely correlated by

$$
\frac{d_{\mathrm{o}}}{D}=A\left(1+\chi \alpha_{\mathrm{o}, \mathrm{av}}\right)(W e)^{-0.6}
$$

which is applicable to a spectrum of cases as indicated in the reviews of Davies (1992) and Peters (1997). The effect of the dispersed phase holdup is represented by the term of $\left(1+\chi \alpha_{\mathrm{o}, \mathrm{av}}\right)$. There were some differences in the reported values of parameters $A$ and $\chi$ (see Table 2), though the functional expression of Eq. (26) was found to work quite well by many researchers. 
Table 2. Values of constants $A$ and $\chi$.

\begin{tabular}{lll}
\hline$A$ & $\chi$ & Reference \\
\hline 0.06 & 9 & (Calderbank, 1958) \\
0.051 & 3.14 & (Brown and Pitt, 1970) \\
0.047 & 2.5 & (van Heuven and Beek, 1971) \\
0.058 & 5.4 & (Mlynek and Resnick, 1972) \\
\hline
\end{tabular}

The values for the constant $A$ are fairly similar, and the ones for $\chi$ vary from 2.5 to 9 . Nevertheless, it is worth noting that $\chi$ is included in the term $\left(1+\chi \alpha_{\mathrm{o}, \mathrm{av}}\right)$. Although $\chi$ changes from 2.5 to 9 , while the term $\left(1+\chi \alpha_{\text {o,av }}\right)$ does not experience considerable change. For example, if $\alpha_{\mathrm{o}, \mathrm{av}}=0.1$, when $\chi=2.5,\left(1+\chi \alpha_{\mathrm{o}, \mathrm{av}}\right)=1.25$; when $\chi=9,\left(1+\chi \alpha_{\mathrm{o}, \mathrm{av}}\right)=1.9$. So the averages over the literature values are used in this study.

The bubble size is approximated by the classic correlation (Bhavaraju et al., 1978; Garcia-Ochoa and Gomez, 2004; Parthasarathy et al., 1991):

$$
d_{\mathrm{b}}=0.7 \frac{\sigma^{0.6}}{\varepsilon^{0.4} \rho_{\mathrm{c}}^{0.2}}\left(\frac{\mu_{\mathrm{c}}}{\mu_{\mathrm{g}}}\right)^{0.1}
$$

Garcia-Ochoa and Gomez (2004) showed that the correlation was valid for both Newtonian and non-Newtonian fluids over a wide range of operating conditions in sparged stirred vessels.

\subsection{Mixing model}

The tracer mixing process occurred in the continuous phase is given by

$$
\frac{\partial\left(\alpha_{\mathrm{c}} c\right)}{\partial t}+\frac{\partial\left(\alpha_{\mathrm{c}} u_{i} c\right)}{\partial x_{i}}=\frac{\partial}{\partial x_{i}}\left(D_{\text {eff }} \frac{\partial \alpha_{\mathrm{c}} c}{\partial x_{i}}\right)
$$


where $D_{\text {eff }}=D_{\text {mol }}+\Gamma_{\mathrm{t}}$. The turbulent diffusivity is computed by dividing the turbulent kinetic viscosity $\left(v_{\mathrm{t}}\right)$ by the turbulent Schmidt number as $\Gamma_{\mathrm{t}}=v_{\mathrm{t}} / S c_{\mathrm{t}}$ and $S c_{\mathrm{t}}=0.7$ and $D_{\text {mol }}=10^{-9} \mathrm{~m}^{2} / \mathrm{s}$ are used in this work. The time history of the tracer concentration is recorded at the coordinates of Probes A and B in order to facilitate benchmark of simulations against the measured results. The dimensionless tracer concentration is expressed as

$$
\bar{c}=\frac{c_{t}-c_{0}}{c_{\infty}-c_{0}}
$$

where $\bar{c}$ is the non-dimensional tracer concentration, $c_{t}$ is the tracer concentration at time $t, c_{0}$ is the tracer concentration at $t=0(\mathrm{~s})$, and $c_{\infty}$ is the fully mixed tracer concentration.

\section{Numerical details}

\subsection{Solver description}

The three dimensional governing equations are discretized based on the finite-volume method and solved using the C++ object-oriented open source CFD platform OpenFOAM (Open, 2011a, 2011b). The released twoPhaseEulerFoam module (Rusche, 2003) is modified and extended to simulate three-phase flows. The appropriate numerical schemes adopted in this work are summarized in Table 3. 
Table 3. Discretization schemes adopted in this work:

$\psi$ is a generic variable, $\nabla^{\perp}$ represents the normal gradient at cell surface,

$(\ldots)_{f}$ stands for the operator of face interpolation (Open, 2011a, 2011b).

\begin{tabular}{ll}
\hline Term & Discretization \\
\hline$\frac{\partial}{\partial t}$ & Euler \\
$\nabla \psi$ & cellLimited Gauss linear 1 \\
$\nabla p$ & Gauss linear \\
$\nabla \cdot \psi$ & linearUpwind cellLimited Gauss linear 1 \\
$\nabla \cdot\left(\mathbf{u}_{i} \alpha_{\varphi}\right)$ & linearUpwind cellLimited Gauss linear 1 \\
$\nabla \cdot\left(\mathbf{u}_{i} \mathbf{u}_{i}\right)$ & linearUpwindV cellMDLimited Gauss linear 1 \\
$\nabla^{2} \psi$ & Gauss linear corrected \\
$\nabla^{\perp} \psi$ & Corrected \\
$(\psi)_{f}$ & Linear \\
\hline
\end{tabular}

The PIMPLE algorithm, which is a merger of the PISO and SIMPLE procedures, is used to take care of the pressure-velocity coupling (Open, 2011b). The resulted sparse matrix systems are solved by means of different iterative solution techniques according to the structure of matrixes. The symmetric pressure equation is solved by the geometric-algebraic multi-grid (GAMG) method with diagonal incomplete Cholesky (DIC) smoother and other asymmetric equations are solved by the preconditioned bi-conjugate gradient (PBiCG) method with diagonal incomplete-Lu (DILU) pre-conditioner (Open, 2011b). For the details of the iterative solvers shipped with OpenFOAM, please refer to the reference (Saad, 2003). 


\subsection{Solution domain and boundary conditions}

The mesh is generated by employing the powerful but tedious blockMesh utility included in the OpenFOAM. The blockMesh utility decomposes the reactor into a number of three dimensional hexahedral blocks, and creates parametric meshes along the edges (straight lines and curved lines) with grading. The boundaries of the domain are defined on the basis of coordinates in the blockMeshDict file. The typical meshing structure used in this work is shown in Figure 2.

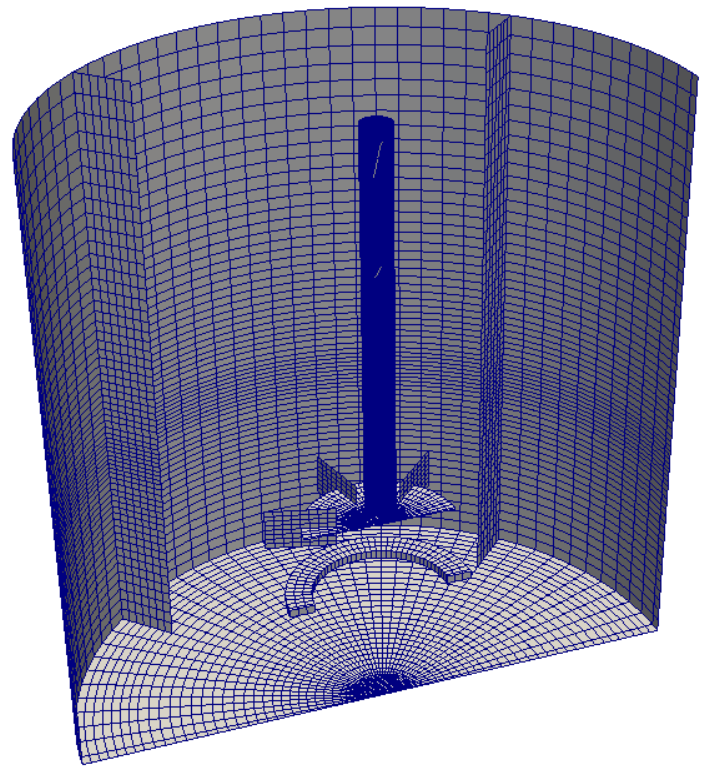

Figure 2. Typical computational grid (cut mid-way between two baffles).

As no symmetry could be assumed in the inert tracer concentration field, the whole vessel is used as the solution domain. Four meshes are considered in the grid independency tests: coarse (265,324cells), medium (413,468 cells), fine $(715,344$ cells) and finer (937,872 cells). It is found that the predicted quantity profiles using the fine and finer mesh are very similar. So, the finer mesh is adopted for subsequent simulations in order to ensure accuracy. The mesh is of good quality with the max skewness is 0.57 , the $\max$ non-orthogonality is 28.9 and the average 
non-orthogonality is 2.8 . The boundary conditions are summarized in Table 4 .

Table 4. Boundary conditions.

\begin{tabular}{ccccc}
\hline Variables & $\alpha_{\mathrm{g}}$ & $\alpha_{\mathrm{o}}, \alpha_{\mathrm{c}}$ & $\varepsilon_{\varphi}$ & $k_{\varphi}$ \\
\hline Solid walls & zeroGradient & zeroGradient & epsilonWallFunction & kqRWallFunction \\
Top surface & inletOutlet & zeroGradient & zeroGradient & zeroGradient \\
Variables & $p$ & $u_{\varphi}$ & & \\
Solid walls & fixedFluxPressure & fixedValue & & \\
Top surface & fixedValue & zeroGradient & & \\
& & & & \\
& & & &
\end{tabular}

The gas is sparged via fvOptions framework in OpenFOAM, which is a powerful feature allowing users to select any physics that can be represented as sources or constraints on the governing equations. The topoSet utility is used to define the cellSet for the gas sparger, and then the gas source is specified on the defined sparger cellSet in the fvOptions file.

The MRF (Multiple Reference Frame) technique is employed to model the impeller rotation in the fully baffled tank by imposing a source term into the momentum equation of the rotor cellzone in MRFProperties file.

The parallel functionality of OpenFOAM relies on the technique of domain decomposition, which splits the whole reactor into a number of sub-domains and solves each one on different processing units. The typical domain decomposition algorithm SCOTCH is applied, which decomposes the whole stirred tank into 20 sub-domains, therefore 20 cores are used as parallel computing. For a typical simulation work, it takes about $5 \sim 6$ days CPU time using the $k-\varepsilon$ model, while the RSM approximately consumes $9 \sim 11$ days 


\section{Results and discussion}

\subsection{Flow field in liquid-liquid systems}

There is no experimental flow field data of gas-liquid-liquid stirred vessel available in the open literature possibly due to measurement difficulties. Therefore, the model performance is first assessed by simulating the immiscible liquid-liquid flows in cylindrical stirred tanks driven by a Rushton turbine and comparing the simulated results to the corresponding experimental data reported in the literature. The experimental conditions are summarized in Table 5.

Table 5. Experimental conditions.

\begin{tabular}{llll}
\hline References & Tank Geometry & \multicolumn{2}{c}{ Immiscible liquid-liquid pair } \\
& & Continuous Phase & Dispersed Phase \\
\hline (Svensson and & $T=0.14 \mathrm{~m}, B=T / 12$, & aqueous NaI solution & silicone oil \\
Rasmuson, & $H=T, D=T / 3, C=T / 3$ & $\rho_{\mathrm{c}}=1340 \mathrm{~kg} / \mathrm{m}^{3}$ & $\rho_{\mathrm{d}}=940 \mathrm{~kg} / \mathrm{m}^{3}$ \\
2004, 2006) & & $\mu_{\mathrm{c}}=0.0014 \mathrm{~Pa} \cdot \mathrm{s}$ & $\mu_{\mathrm{d}}=0.011 \mathrm{~Pa} \cdot \mathrm{s}$ \\
& & & $n$-hexane \\
(Wang and & $T=0.154 \mathrm{~m}, B=T / 12$, & $\mathrm{tap}$ water & $\rho_{\mathrm{d}}=1000 \mathrm{~kg} / \mathrm{m}^{3}$ \\
& $D=T / 4, C=T / 3$ and & $\rho_{\mathrm{c}}=1000 \mathrm{~kg} / \mathrm{m}^{3}$ & $\mu_{\mathrm{d}}=0.001 \mathrm{~Pa} \cdot \mathrm{s}$ \\
& $T / 2$ & $\mu_{\mathrm{c}}=0.001 \mathrm{~Pa} \cdot \mathrm{s}$ & \\
\hline
\end{tabular}

Svensson and Rasmuson (2004) measured the velocity fileds of the continuous phase in the upper and lower circulation zones by means of LDA technique, and later they (Svensson and Rasmuson, 2006) determined the continuous phase velocity fields in the impeller region using the PIV method. The comparisons of predicted mean velocity components of the continuous phase with the measurements are illustrated in 
Figures 3 and 4. As seen, the results predicted from both models are generally in reasonable agreement with the measured data. It is noticed that the RSM predictions are marginally closer to the experimental data than the $k-\varepsilon$ model in the upper and lower circulation zones, while show an appreciable improvement near the impeller tip in the impeller zone. There are palpable discrepancies between predictions by the $k-\varepsilon$ model and the measured data close to the impeller tip. This is possibly because isotropy is assumed in the $k-\varepsilon$ model, whereas anisotropic turbulence is the strongest in the impeller zone.

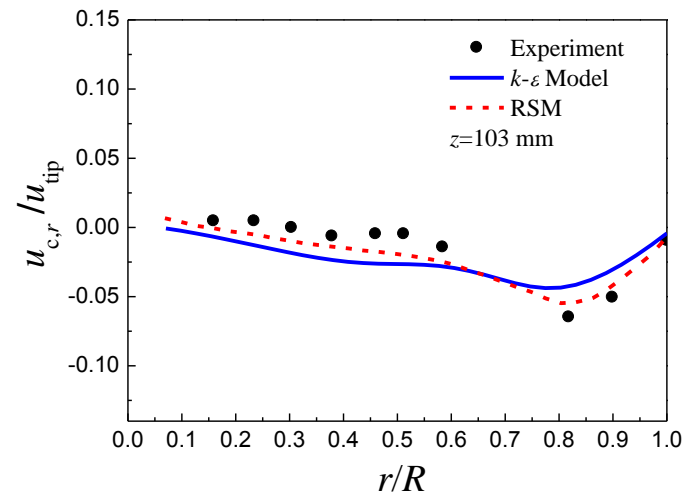

(a)

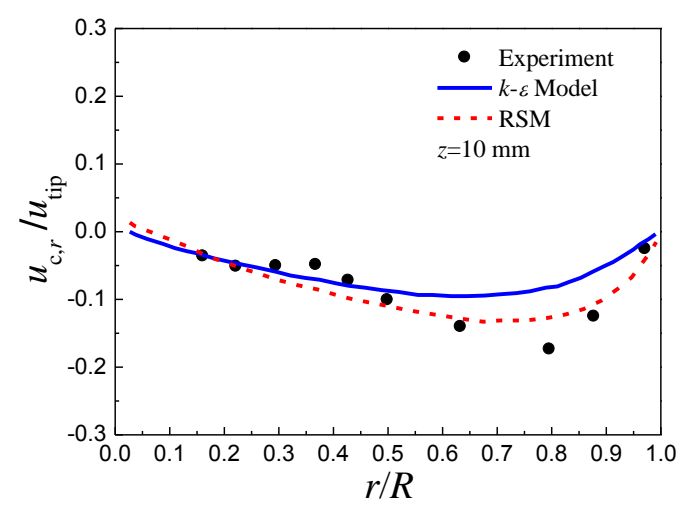

(c)

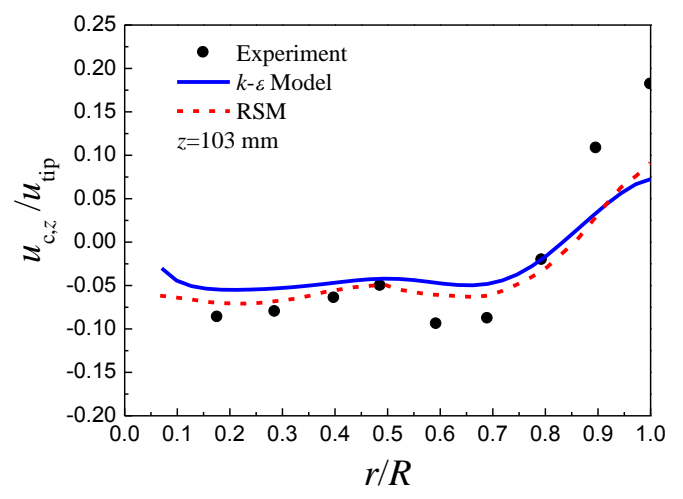

(b)

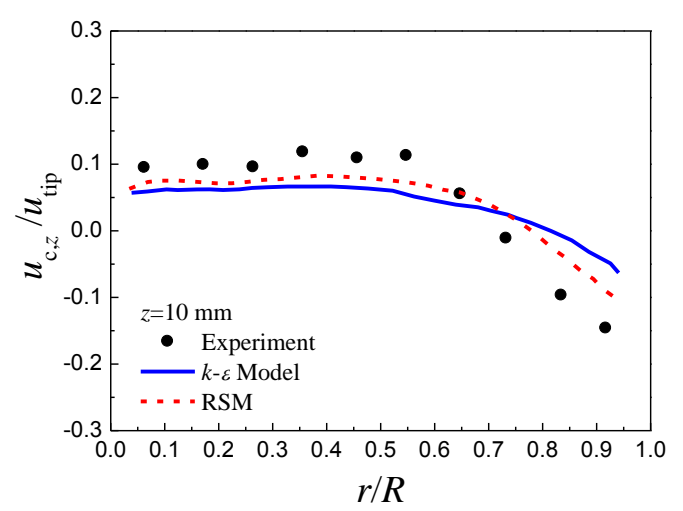

(d)

Figure 3. Comparison of predicted mean velocities with experimental data

$$
\left(N=540 \mathrm{rpm}, \quad \alpha_{\mathrm{o}, \mathrm{av}}=10 \%\right) \text {. }
$$




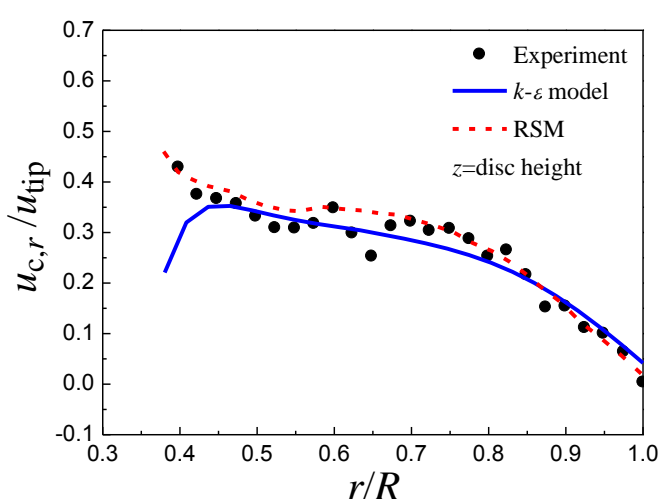

(a)

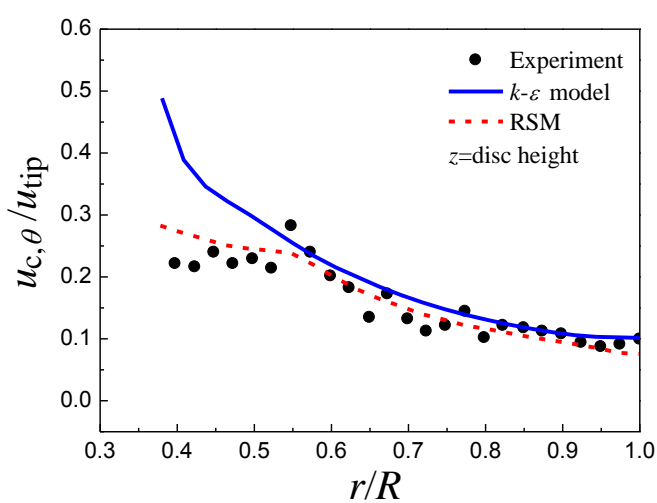

(b)

Figure 4. Comparison of predicted mean velocities with experimental data

$$
\left(N=540 \mathrm{rpm}, \alpha_{\text {o,av }}=7 \%\right) .
$$

The models are further evaluated by means of comparing the predicted oil holdup distributions to the corresponding experimental data of Wang and Mao (2005), in which the local oil holdup profiles were measured using the sample withdrawal method.

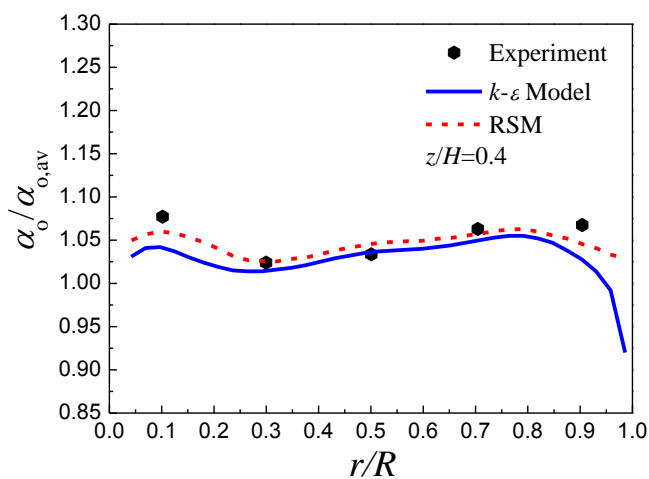

(a)

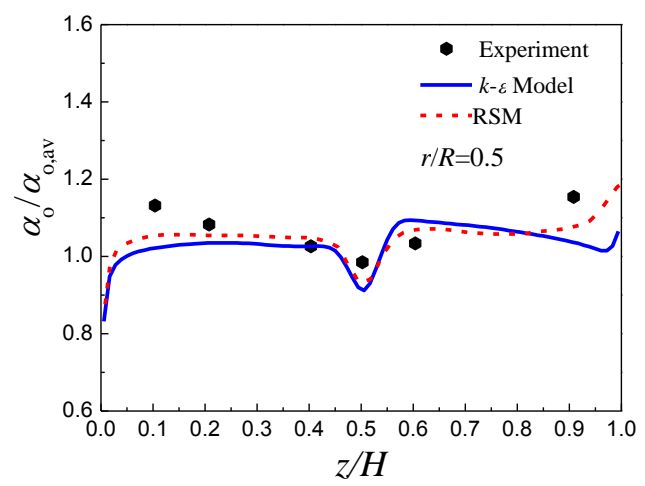

(c)

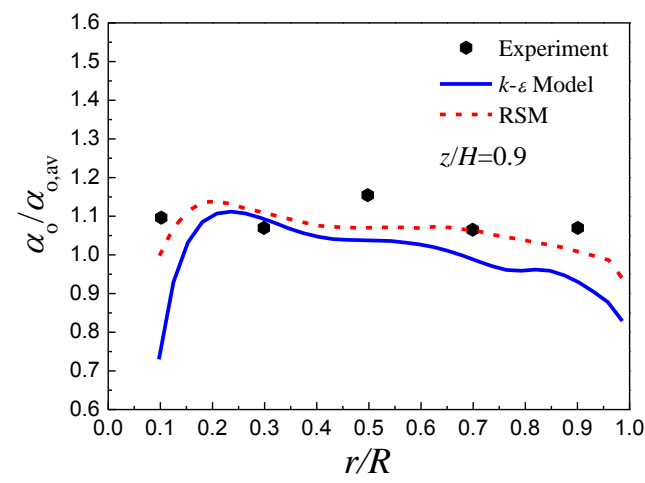

(b)

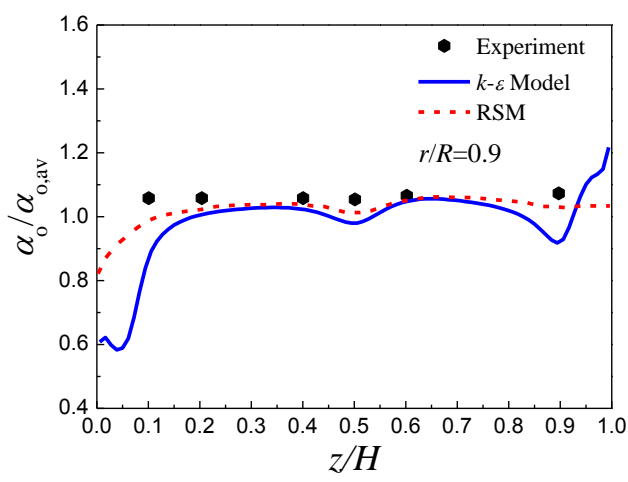

(d) 
Figure 5. Comparison of predicted oil phase holdup profiles with experimental data $\left(N=400 \mathrm{rpm}, C=T / 2, \quad \alpha_{\mathrm{o}, \mathrm{av}}=10 \%\right)$.

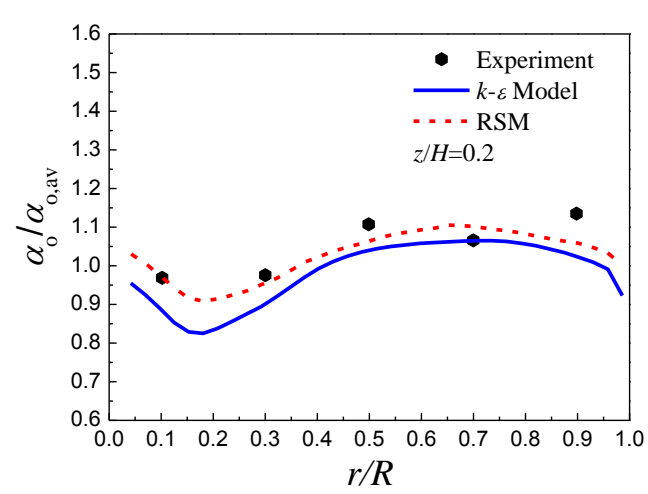

(a)

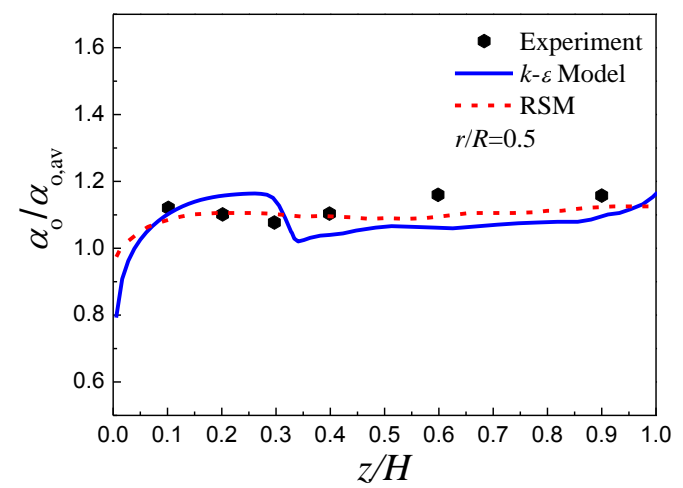

(c)

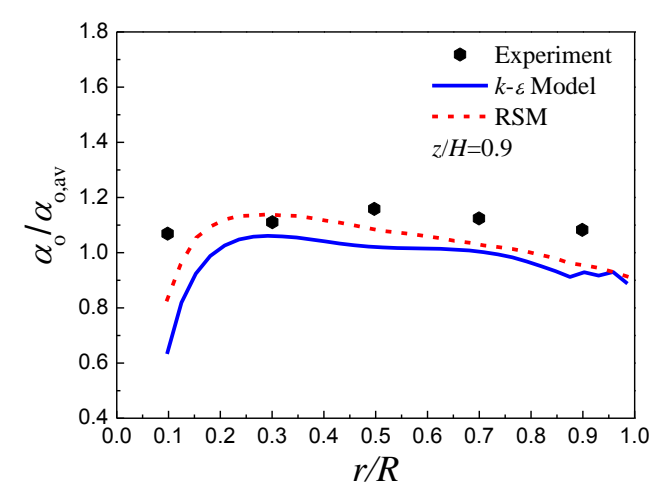

(b)

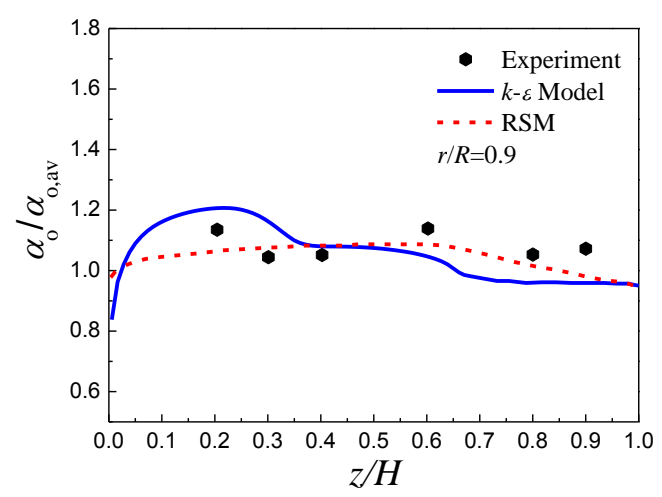

(d)

Figure 6. Comparison of predicted oil phase holdup profiles with experimental data

$$
\left(N=400 \mathrm{rpm}, C=T / 3, \alpha_{\mathrm{o}, \mathrm{av}}=10 \%\right) .
$$

Figures 5 and 6 show the comparisons of simulated oil holdup distributions with the measured data. It is observed that both turbulence models tend to underestimate the values of oil phase holdup near the vessel wall and the bottom. However, considering the complex coalescence and breakage phenomena is not accounted for in the numerical models, therefore, the overall agreement between the model predictions and the experimental data is generally satisfactory. Some differences can be seen between the predictions by the two turbulence models, and the RSM reveals an improvement in contrast with the $k-\varepsilon$ model. The reasonably good agreement illustrates that the present numerical models can satisfactorily capture the main mean 
flow characteristics in the turbulent liquid-liquid stirred vessels.

\subsection{Bulk flow characteristics in gas-liquid-liquid systems}

As the simulated flow fields by the $k-\varepsilon$ model and the RSM qualitatively look alike to each other. So the typical flow fields predicted by the $k-\varepsilon$ model are presented in this section for the sake of brevity.

The gas holdup contour plots at a slice cut from mid-way between two baffles (the relative location of the plane is referred to Figure 2) at various agitation speeds are shown in Figure 7. As seen, the sparged gas flows upwards with being just slightly dispersed by the turbine at a low impeller speed (Figure 7a), then more gas is dispersed by the impeller motion as agitation speed increases (Figure 7b), the upper bulk region becomes full of gas bubbles (Figure 7c), and finally gas is entrained into the lower bulk zone (Figure 7d). The higher agitation speed, the more gas is dispersed into the region below the impeller. The predicted variation of gas holdup distributions is topologically similar to the experimental observations in a gas-liquid stirred tank reported in the literature (e.g., Wang et al., 2006b).

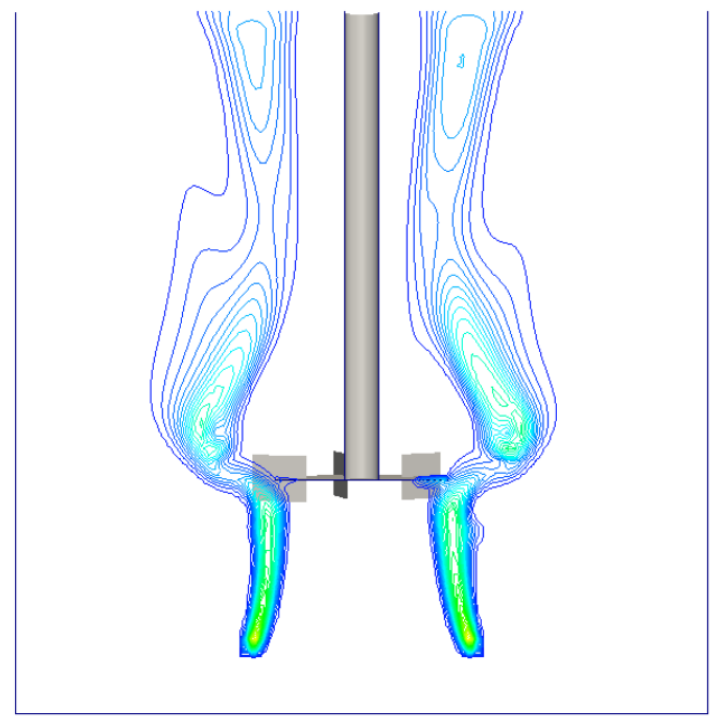

(a) $N=170 \mathrm{rpm}$

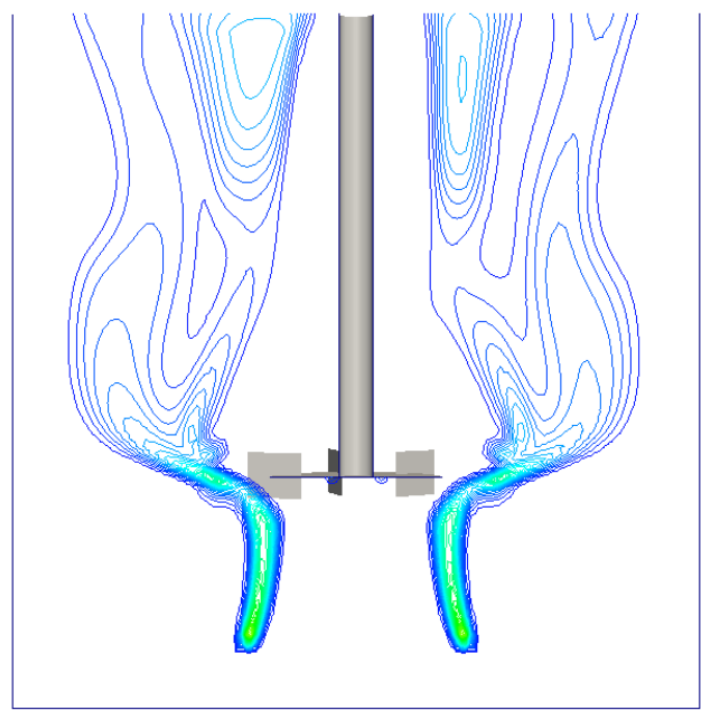

(b) $N=220 \mathrm{rpm}$ 


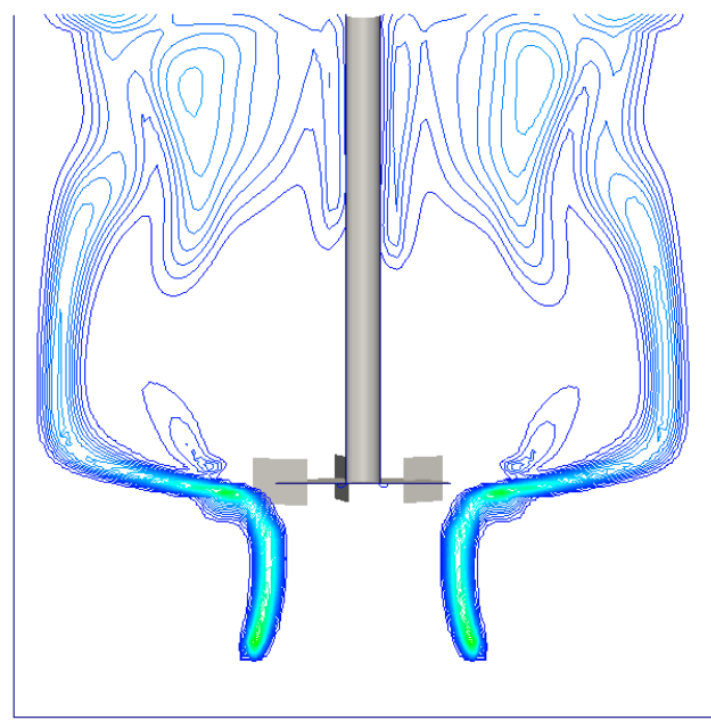

(c) $N=300 \mathrm{rpm}$

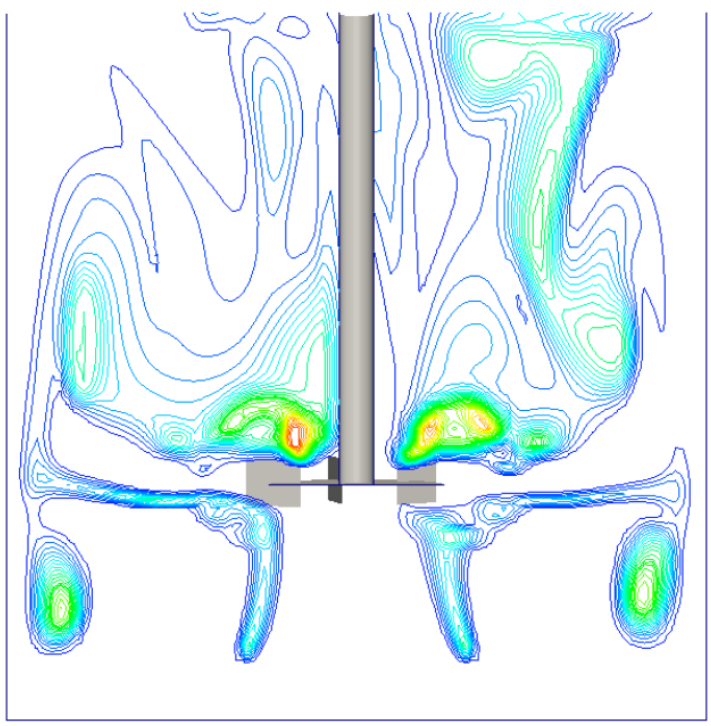

(d) $N=500 \mathrm{rpm}$

Figure 7. Predicted gas holdup contour map at a slice cut from mid-way between two baffles $\left(\alpha_{\mathrm{o}, \mathrm{av}}=1.0 \%, Q_{\mathrm{G}}=0.40 \mathrm{~L} / \mathrm{min}\right)$.

The predicted velocity fields of the gas phase and the continuous phase are shown in Figures 8 and 9. As seen, the double-loop flow structure produced by the radial disc turbine is captured.

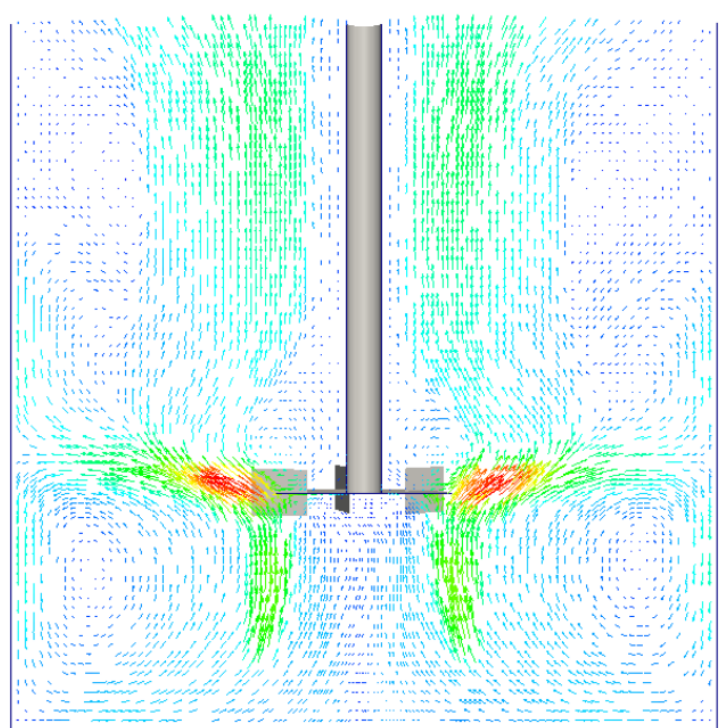

(a) $N=170 \mathrm{rpm}$

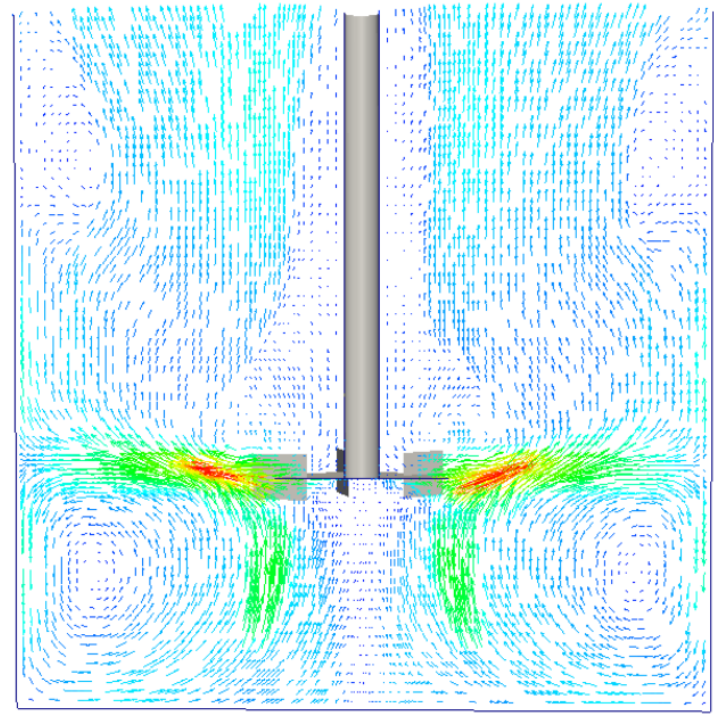

(b) $N=220 \mathrm{rpm}$ 


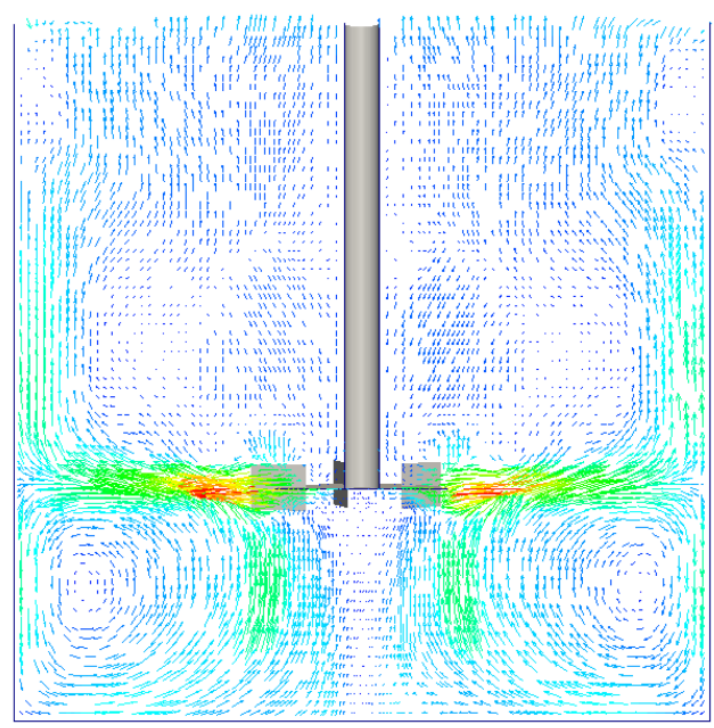

(c) $N=300 \mathrm{rpm}$

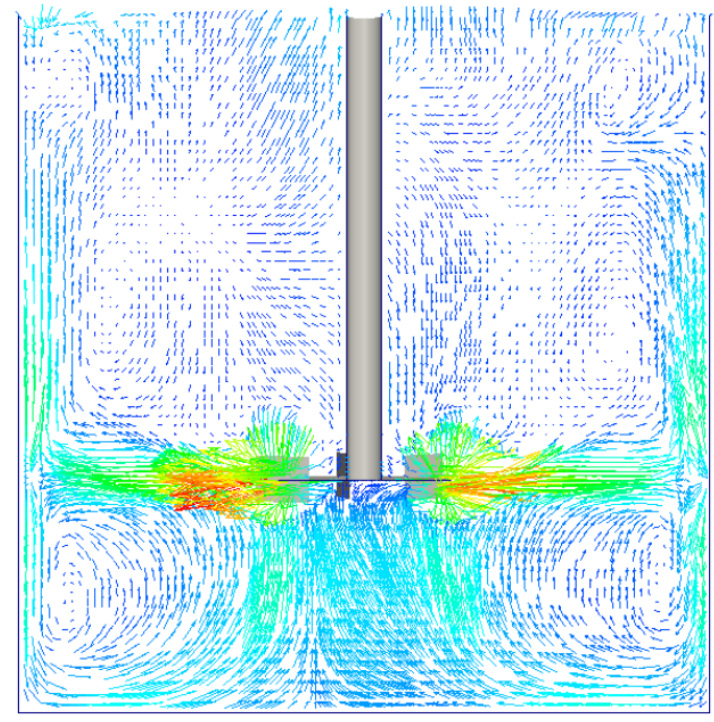

(d) $N=500 \mathrm{rpm}$

Figure 8. Predicted gas velocity vectors at a slice cut from mid-way between two baffles $\left(\alpha_{\mathrm{o}, \mathrm{av}}=1.0 \%, Q_{\mathrm{G}}=0.40 \mathrm{~L} / \mathrm{min}\right)$.

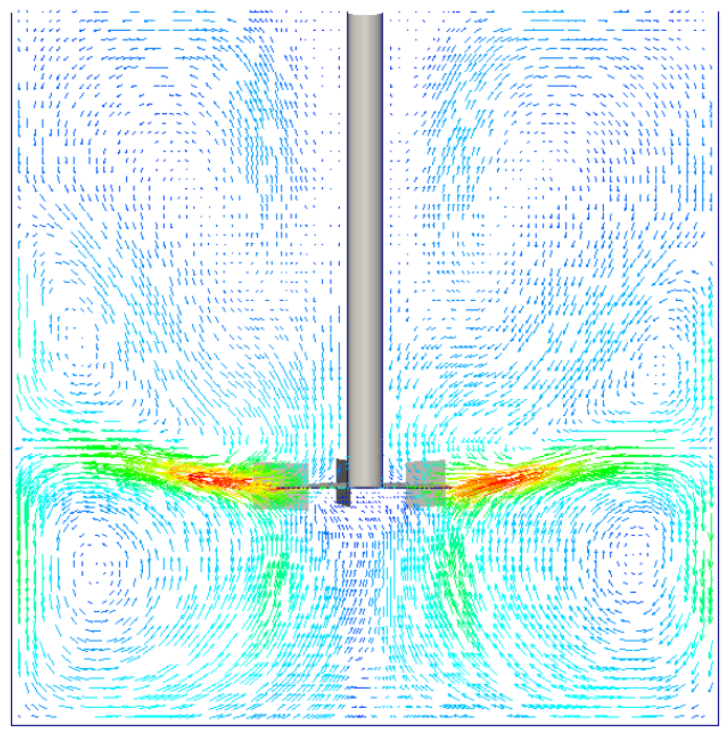

(a) $N=170 \mathrm{rpm}$

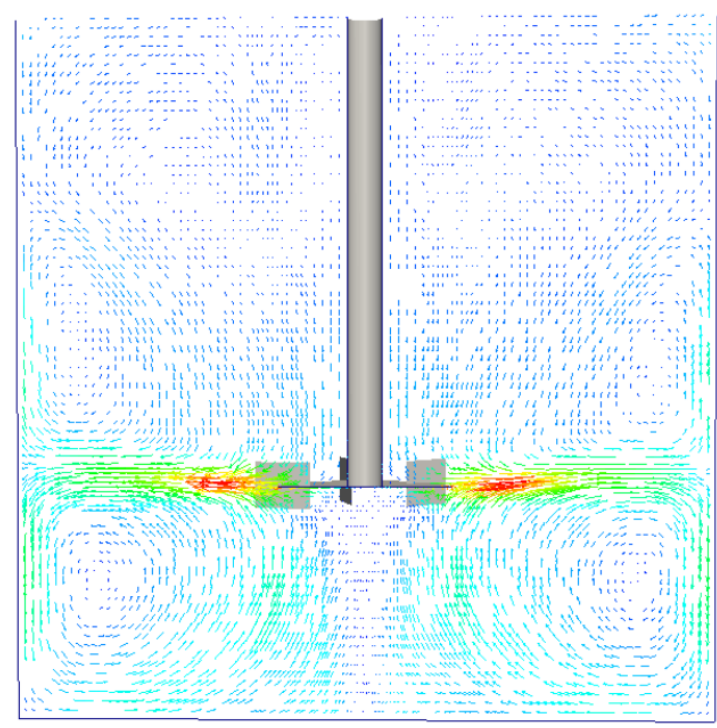

(b) $N=220 \mathrm{rpm}$ 


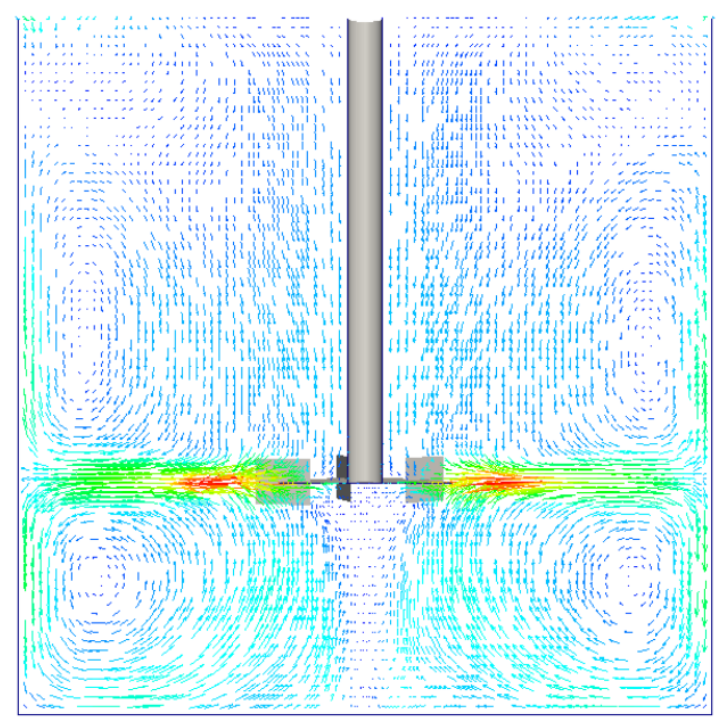

(c) $N=300 \mathrm{rpm}$

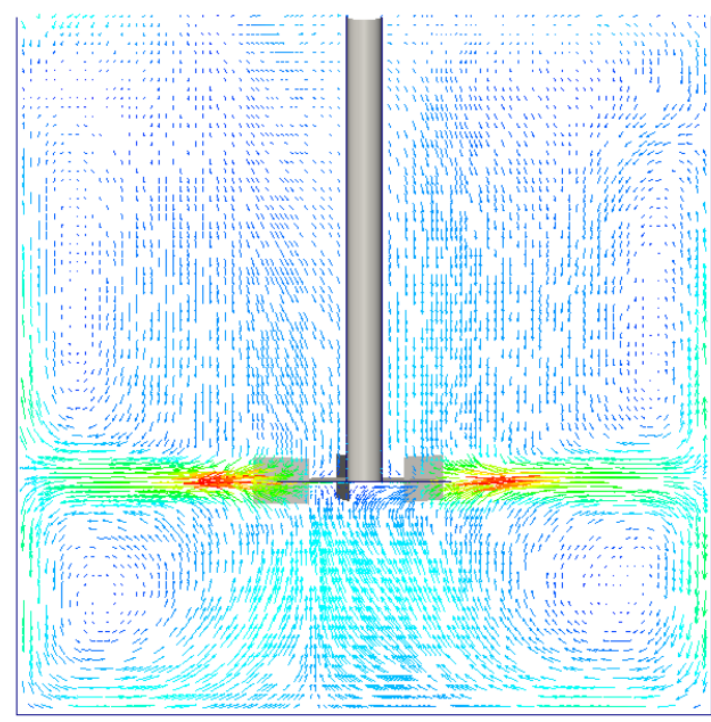

(d) $N=500 \mathrm{rpm}$

Figure 9. Predicted continuous phase velocity vectors at a slice cut from mid-way between two baffles $\left(\alpha_{\mathrm{o}, \mathrm{av}}=1.0 \%, Q_{\mathrm{G}}=0.40 \mathrm{~L} / \mathrm{min}\right)$.

The upward inclination of impeller discharge stream is observed at the flooding regime (see Figures $8 \mathrm{a} \& 9 \mathrm{a}$ ), which is induced by the sparging gas. It is noted that there are secondary circulation loops in the continuous phase of the gas-liquid-liquid dispersion above the turbine in Figure 9a, which is analogous to the observation in gas-liquid stirred tanks driven by a Rushton turbine at flooding regimes (Khopkar et al., 2005; Scargiali et al., 2007; Wang et al., 2006b).

\subsection{Mixing in gas-liquid-liquid systems}

The homogenization curve of normalized concentration and mixing time are needed in order to effectively characterize the macro-mixing process. The homogenization curve reveals the local mixing characteristics while the mixing time is a key performance index to evaluate a mixer.

\subsubsection{Homogenization}

The predicted homogenization curves are shown alongside with the 
corresponding experimental ones from aerated liquid-liquid systems in Figure 10. We can see that the signals are affected by the motions of bubbles and droplets and the measured curves first ascend steeply to peaks, and then decay over time until fully mixed. Generally speaking, both models have well captured the mixing trends, and the predicted curves by the RSM are closer to the experimental ones than those by the $k-\varepsilon$ model. As the quality of simulated macro-mixing processes are dependent on the overall accuracy of the calculated flow field. The comparisons in Figure 10 also indicate that the slight improvements in the simulated flow field (see Figures $3 \sim 6$ ) by RSM could be accumulated to lead to more appreciable improvement in the description of mixing processes. So the comparisons of homogenization curves further illustrate that the RSM gives better globally predictive capability than the $k$ - $\varepsilon$ model.

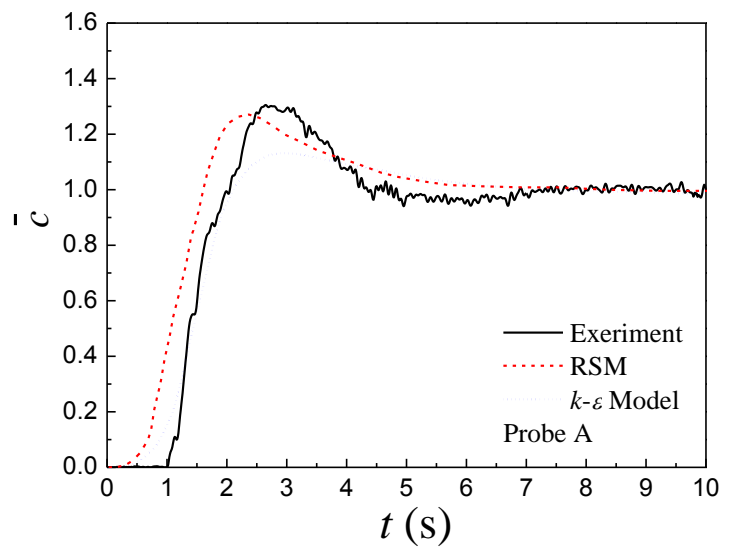

(a) Probe A

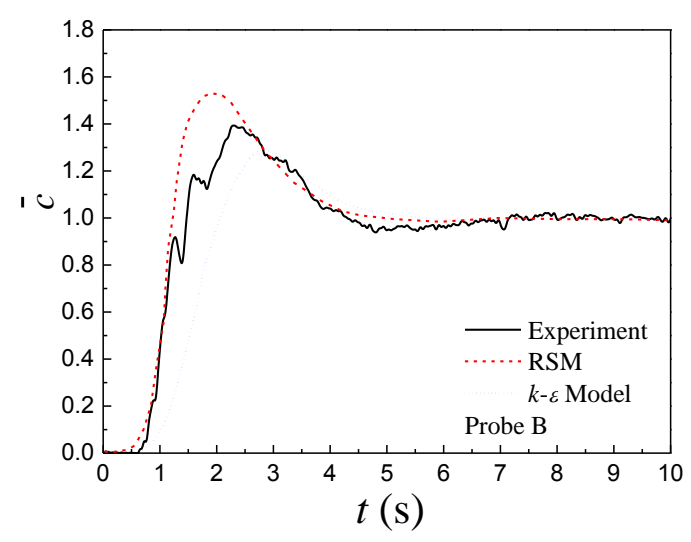

(b) Probe B

Figure 10. Comparisons of simulated homogenization curves with experimental ones

$$
\left(N=400 \mathrm{rpm}, \alpha_{\mathrm{o}, \mathrm{av}}=10 \%, Q_{\mathrm{G}}=0.32 \mathrm{~L} / \mathrm{min} .\right)
$$

\subsubsection{Mixing time in gas-liquid-liquid systems}

The comparisons of predicted mixing time with the measured data can facilitate a quantitative evaluation of different turbulence models under various conditions, e.g., varying oil holdups and gas flow rates. 


\subsubsection{Effect of oil holdup}

The effect of oil holdup on mixing time of the continuous phase in gas-liquid-liquid systems is shown in Figure 11. As can be seen, the measured values of mixing time decline initially and then go up. The predictions correspond reasonably to this trend, which indicates that the numerical models can capture the essential features of such stirred gas-liquid-liquid systems.

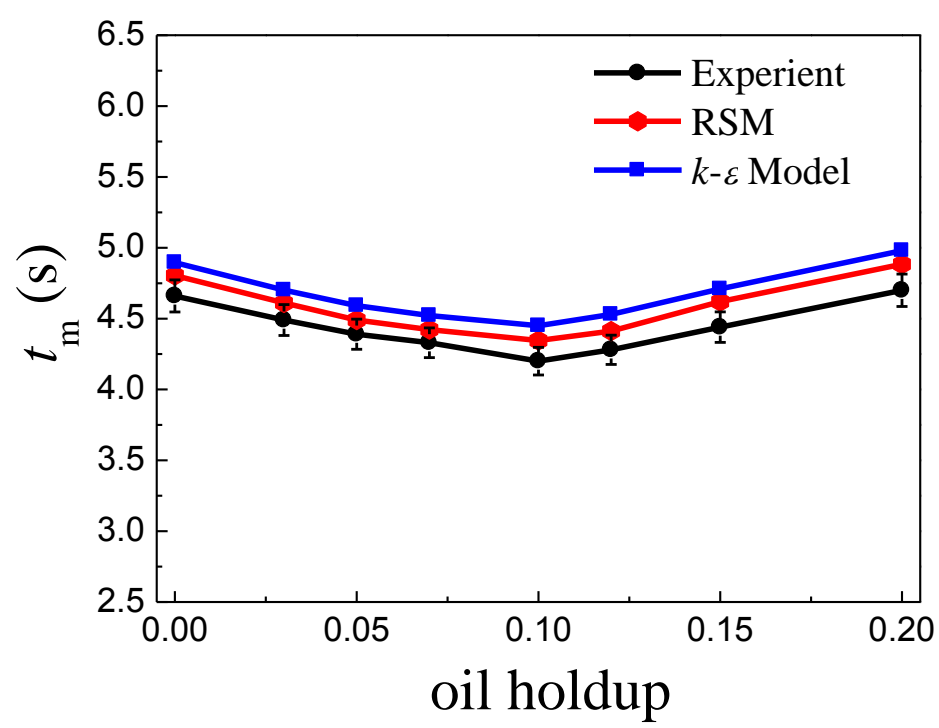

Figure 11. Mixing time versus oil holdup ( $\left.N=425 \mathrm{rpm}, Q_{\mathrm{G}}=0.48 \mathrm{~L} / \mathrm{min}\right)$.

Zhao et al. (2011) reported silimiar continuous phase mixing time trend in a liquid-liquid system, and they analyzed that the continuous phase turbulence was enhanced by vortex shedding at lower oil holdups while dampened at higher values of oil holdups. Their analysis was well supported by some experiments (see Laurenzi et al., 2009; Svensson and Rasmuson, 2004, 2006). Das et al. (1985) determined the gas-liquid interfacial area per unit volume of the dispersion in the presence of an inert oil phase in a stirred tank by means of an optical method, and reported that the gas-liquid interfacial area had a maximum value at around $\alpha_{0, a v}=10 \%$ when the oil 
holdup was increased. Their further bubble size experiments revealed that the oil phase tended to dampen the continuous phase turbulence, which brought down the gas-liquid interfacial area at higher oil holdups.

On the other hand, our previous work (Cheng et al., 2013) suggested examining the flow number and circulation number with the dispersed phase holdup to understand the variation of the continuous phase mixing time, as mixing time is closely related to the two numbers according to the bulk flow model (Nere et al., 2003; Nienow, 1990, 1997). van de Vusse (1955) revealed that the pumping capacity plays a major role in determination of mixing time in a stirred tank. Later, Cooper and Wolf (1967) reported that the intensity of segregation is almost linearly dependent on the reciprocal of pumping capacity. Therefore, the flow number $(F l)$ and the circulation flow number $\left(F l_{\mathrm{c}}\right)$ are calculated by (Costes and Couderc, 1988; Jaworski et al., 1996)

$$
\begin{gathered}
F l=\frac{\int_{-w / 2}^{w / 2} \int_{\theta=0}^{\theta=2 \pi} r u_{\mathrm{c}, r} \mathrm{~d} \theta \mathrm{d} Z}{N D^{3}} \\
F l_{c}=\frac{\int_{0}^{r_{0}} 2 \pi u_{\mathrm{c}, z L} r \mathrm{~d} r+\int_{r_{0}}^{T / 2} 2 \pi u_{\mathrm{c}, z U} r \mathrm{~d} r}{N D^{3}}
\end{gathered}
$$

where $r_{0}$ refers to the radial coordinate of the center of circulation loop. The subscripts $L$ and $U$ represent the lower and the upper circulation loop respectively.

To see if the numerical models can return reasonable values of $F l$ and $F l_{\mathrm{c}}$, the single phase stirred tank filled with water agitated by a Rushton turbine is simulated (see Table 6) because of its values of $F l$ and $F l_{\mathrm{c}}$ were well documented in the literature. As can be seen from Table 6, the predicted $F l$ and $F l_{c}$ are close to the experimental counterparts. 
Table 6. Simulated flow data in single phase stirred tanks.

\begin{tabular}{ccccc}
\hline Sources & $($ Revill, 1982) & $($ Strek, 1977) & $k$ - $\varepsilon$ model & RSM \\
\hline$F l$ & $0.6 \sim 0.9$ & $0.73 \sim 1.02$ & 0.82 & 0.90 \\
Sources & $($ Jaworski et al., 1996) & $($ Revill, 1982) & $k$ - $\varepsilon$ model & RSM \\
$F l_{\mathrm{c}}$ & 2.10 & $1.37 \sim 2.05$ & 2.27 & 2.40 \\
\hline
\end{tabular}

The computed values of $F l$ and $F l_{\mathrm{c}}$ from the present gas-liquid-liquid stirred vessels are listed in Table 7. We can see that the flow data obtained from the $k-\varepsilon$ model are slightly smaller than those predicted by the RSM. Taking into account that the RSM simulations are closer to the measured mixing time, this information indicates that the over-prediction of mixing time values could possibly be attributed to under-prediction of overall velocity field.

Table 7. Simulated flow data versus oil holdup ( $\left.N=425 \mathrm{rpm}, Q_{\mathrm{G}}=0.48 \mathrm{~L} / \mathrm{min}\right)$.

\begin{tabular}{lcccccccc}
\hline \multicolumn{1}{c}{$\alpha_{\mathrm{o}, \mathrm{av}}$} & & $0 \%$ & $3 \%$ & $5 \%$ & $7 \%$ & $12 \%$ & $15 \%$ & $20 \%$ \\
\hline \multirow{2}{*}{$k$ - $\varepsilon$ model } & $F l$ & 0.63 & 0.62 & 0.61 & 0.60 & 0.55 & 0.50 & 0.46 \\
& $F l_{\mathrm{c}}$ & 1.93 & 1.92 & 1.92 & 1.90 & 1.83 & 1.76 & 1.70 \\
& $F l$ & 0.66 & 0.65 & 0.64 & 0.63 & 0.57 & 0.52 & 0.47 \\
& $F l_{\mathrm{c}}$ & 2.05 & 2.04 & 2.03 & 2.02 & 1.94 & 1.86 & 1.78 \\
\hline
\end{tabular}

We can see that the values of $F l$ and $F l_{c}$ vary with the oil holdup, and they are obviously smaller when $\alpha_{\mathrm{o}, \mathrm{av}} \geq 12 \%$. The variation is helpful for us to have a better understanding of the influence of oil holdup on the continuous phase mixing time.

\subsubsection{Effect of gas flow rate}


Figure 12 plots the effect of gas flow rate on the continuous phase mixing time. As seen, the predicted mixing time is close to the measured data. The computed values of $F l$ and $F l_{\mathrm{c}}$ with varying gas flow rates are listed in Table 8 .

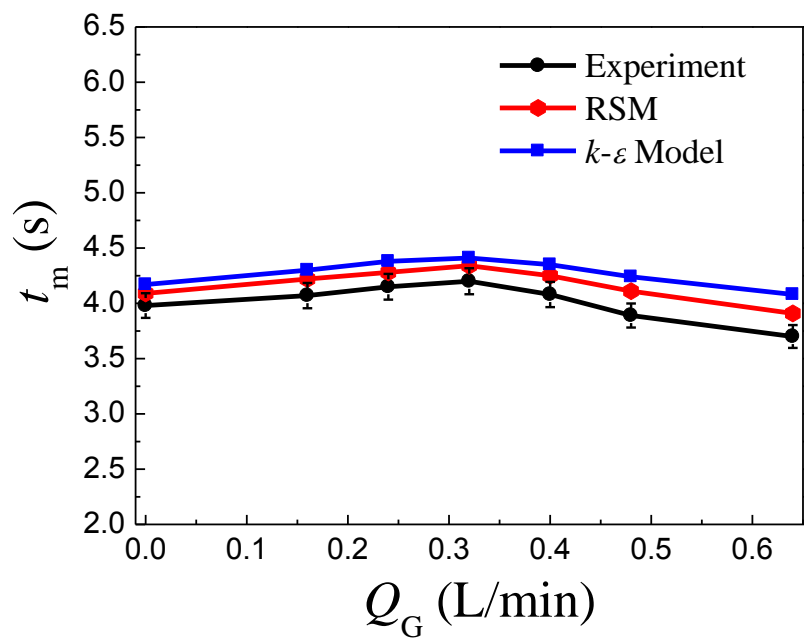

Figure 12. Mixing time versus gas flow rate ( $\left.N=440 \mathrm{rpm}, \alpha_{\mathrm{o}, \mathrm{av}}=10 \%\right)$.

Table 8. Simulated flow data versus gas flow rate $\left(N=440 \mathrm{rpm}, \alpha_{\mathrm{o}, \mathrm{av}}=10 \%\right)$.

\begin{tabular}{lcccccccc}
\hline \multicolumn{2}{c}{$Q_{\mathrm{G}}(\mathrm{L} / \mathrm{min})$} & 0 & 0.16 & 0.24 & 0.32 & 0.4 & 0.48 & 0.64 \\
\hline$k-\varepsilon$ model & $F l$ & 0.80 & 0.74 & 0.64 & 0.57 & 0.56 & 0.55 & 0.54 \\
& $F l_{\mathrm{c}}$ & 2.23 & 2.13 & 1.95 & 1.86 & 1.85 & 1.85 & 1.84 \\
& $F l$ & 0.86 & 0.76 & 0.67 & 0.59 & 0.58 & 0.57 & 0.56 \\
$\mathrm{RSM}$ & $F l_{\mathrm{c}}$ & 2.27 & 2.15 & 2.07 & 1.98 & 1.98 & 1.97 & 1.96 \\
\hline
\end{tabular}

As seen, $F l$ and $F l_{\mathrm{c}}$ decrease with increasing gas flow rate. The quantitative information can help us understand the influence of gas flow rate on the mixing time of the continuous phase. However, the slight decrease in mixing time at higher gas flow rates is probably because of the bubbles induced agitation increases the overall 
intensity of mixing.

\section{Conclusion}

The turbulent flow and macro-mixing processes in gas-liquid-liquid flat-bottomed stirred reactors agitated by a Rushton turbine have been numerically simulated based on the Eulerian multi-fluid approach using the RANS technique. Both the isotropic $k-\varepsilon$ model and the anisotropic Reynolds stress model are adopted. The numerical models are validated by means of comparing simulated flow field of agitated immiscible liquid-liquid dispersions to the corresponding experimental data from the literature. The predicted time traces of normalized concentrations and values of mixing time in the continuous phase of gas-liquid-liquid stirred tanks are compared to the experimentally measured ones in order to assess the predictive capabilities of the present numerical models for three-phase turbulent flows.

Both the $k-\varepsilon$ model and the RSM correspond reasonably well to the experimental data in both turbulent liquid-liquid and gas-liquid-liquid stirred vessels. The anisotropic RSM produces better results in terms of flow field, homogenization curves and mixing time values than the isotropic $k-\varepsilon$ model. While the improved accuracy of the RSM model comes at the cost of more computational time. The findings suggest that advanced turbulence modeling such as RSM is encouraged to consider when the computational time is not the first concern. However, if the primary priority is to obtain reasonable results for a faster assessment of the relevant processes, the popular $k-\varepsilon$ model would be good enough, especially for industrial-scale applications.

Overall, the complicated gas-liquid-liquid turbulent flows and mixing processes in stirred reactors can be simulated with good accuracy on OpenFOAM, and better results would be reached if a more advanced turbulence model such as the anisotropic 
RSM is used.

\section{Acknowledgements}

Financial supports from National Key Research and Development Program (2016YFB0301701), the National Natural Science Foundation of China (21376243, 91434126), the Major National Scientific Instrument Development Project (21427814) and Jiangsu National Synergetic Innovation Center for Advanced Materials are gratefully acknowledged.

\section{Nomenclature}
A constant
c tracer concentration, $\mathrm{g} / \mathrm{m}^{3}$
C off-bottom distance, $\mathrm{m}$
$C_{\mathrm{D}} \quad$ drag coefficient
$d \quad$ diameter of drop, $\mathrm{m}$
D impeller diameter, $\mathrm{m}$
$D_{\text {eff }} \quad$ effective diffusion coefficient, $\mathrm{m}^{2} / \mathrm{s}$
$D_{\text {mol }} \quad$ molecular diffusion coefficient, $\mathrm{m}^{2} / \mathrm{s}$
$F l \quad$ flow number
$F l_{\mathrm{c}} \quad$ circulation number
F interphase interaction forces
$g \quad$ acceleration due to gravity, $\mathrm{m} / \mathrm{s}^{2}$
H liquid height, $\mathrm{m}$ 


$\begin{array}{ll}k & \text { turbulent kinetic energy, } \mathrm{m}^{2} / \mathrm{s}^{2} \\ N & \text { impeller agitation speed, } \mathrm{rpm} \\ p & \text { pressure, } \mathrm{Pa} \\ r & \text { radial coordinate, } \mathrm{m} \\ r_{0} & \text { radial position of the center of circulation loop } \\ t & \text { time, } \mathrm{s} \\ t_{\mathrm{m}} & \text { mixing time, } \mathrm{s} \\ T & \text { tank diameter, } \mathrm{m} \\ u & \text { velocity component, } \mathrm{m} / \mathrm{s} \\ u_{\text {tip }} & \text { velocity of impeller tip, } \mathrm{m} / \mathrm{s} \\ w & \text { impeller blade width, } \mathrm{m} \\ Z & \end{array}$

\section{Greek letters}

$\begin{array}{ll}\alpha & \text { dispersed phase holdup } \\ \varepsilon & \text { turbulent kinetic energy dissipation rate, } \mathrm{m}^{2} / \mathrm{s}^{3} \\ \mu & \text { dynamic viscosity, } \mathrm{Pa} \cdot \mathrm{s} \\ \mu_{\mathrm{t}} & \text { turbulent dynamic viscosity,Pa. } \\ v & \text { kinetic viscosity, } \mathrm{m}^{2} / \mathrm{s} \\ v_{\mathrm{t}} & \text { turbulent kinetic viscosity, } \mathrm{m}^{2} / \mathrm{s} \\ \chi & \text { constant } \\ \rho & \text { density, } \mathrm{kg} / \mathrm{m}^{3}\end{array}$




$\begin{array}{ll}\sigma & \text { interfacial tension, } \mathrm{N} / \mathrm{m}^{2} \\ \varphi & \text { phase } \\ \Gamma_{\mathrm{t}} & \text { turbulent diffusion coefficient, } \mathrm{m}^{2} / \mathrm{s} \\ \theta & \text { azimuthal coordinate, }{ }^{\mathrm{o}}\end{array}$

\section{Subscripts}

$\begin{array}{ll}\text { av } & \text { averaged } \\ \mathrm{b} & \text { bubble } \\ \mathrm{c} & \text { continuous phase } \\ \mathrm{d} & \text { dispersed phase } \\ \mathrm{drag} & \text { drag force } \\ \text { eff } & \text { effective } \\ \mathrm{g} & \text { gas phase } \\ i, j, k, l, m, n & \text { radial, tangential or axial directions } \\ \mathrm{m} & \text { mixing } \\ r & \text { radial direction } \\ \mathrm{t} & \text { turbulent } \\ z & \text { axial direction } \\ \text { tip } & \text { impeller tip } \\ \theta & \text { tangential direction }\end{array}$




\section{Reference}

Barnea, E., Mizrahi, J., 1975. A generalised approach to the fluid dynamics of particulate systems part 2: Sedimentation and fluidisation of clouds of spherical liquid drops. The Canadian Journal of Chemical Engineering 53, 461-468.

Beishuizen, N., Naud, B., Roekaerts, D., 2007. Evaluation of a modified Reynolds stress model for turbulent dispersed two-phase flows including two-way coupling. Flow, Turbulence and Combustion 79, 321-341.

Bhavaraju, S.M., Russell, T., Blanch, H., 1978. The design of gas sparged devices for viscous liquid systems. AIChE Journal 24, 454-466.

Brown, D.E., Pitt, K., 1970. Drop size for breakup in a stirred liquid-liquid contactor. In: Chemeca-Proceedings of Australian Chemical Engineering Conference. Butterworths and the Institution of Chemical Engineerings, Chemical Engineering Congress: Chatswood, NSW, Australia, vol. 83, pp. 83-97.

Brucato, A., Grisafi, F., Montante, G., 1998. Particle drag coefficients in turbulent fluids. Chemical Engineering Science 53, 3295-3314.

Calderbank, P.H., 1958. Physical rate processes in industrial fermentation. Transactions of the Institutions of Chemical Engineers 37, 171-185.

Cheng, D., Cheng, J.C., Li, X.Y., Wang, X., Yang, C., Mao, Z.-S., 2012. Experimental study on gas-liquid-liquid macro-mixing in a stirred tank. Chemical Engineering Science 75, 256-266.

Cheng, D., Feng, X., Cheng, J.C., Yang, C., 2013. Numerical simulation of macro-mixing in liquid-liquid stirred tanks. Chemical Engineering Science 101, $272-282$

Cokljat, D., Slack, M., Vasquez, S., Bakker, A., Montante, G., 2006. Reynolds-stress model for Eulerian multiphase. Progress in Computational Fluid Dynamics, An 
International Journal 6, 168-178.

Cooper, R., Wolf, D., 1967. Pumping capacities in stirred tanks theory and application. The Canadian Journal of Chemical Engineering 45, 197-203.

Costes, J., Couderc, J., 1988. Study by laser Doppler anemometry of the turbulent flow induced by a Rushton turbine in a stirred tank: influence of the size of the units-I. Mean flow and turbulence. Chemical Engineering Science 43, 2751-2764.

Daly, B.J., Harlow, F.H., 1970. Transport equations in turbulence. Physics of Fluids 13, 2634-2649.

Das, T., Bandopadhyay, A., Parthasarathy, R., Kumar, R., 1985. Gas-liquid interfacial area in stirred vessels: The effect of an immiscible liquid phase. Chemical Engineering Science 40, 209-214.

Davies, G.A., 1992. Mixing and coalescence phenomena in liquid-liquid systems. In Science and practice of liquid-liquid extraction,Thornton, J.D. Eds.; Clarendon Press: Oxford, U.K., Vol. 1, pp.245-342.

Dumont, E., Delmas, H., 2003. Mass transfer enhancement of gas absorption in oil-in-water systems: a review. Chemical Engineering and Processing 42, $419-438$.

Feng, X., Li, X.Y., Cheng, J.C., Yang, C., Mao, Z.-S., 2012. Numerical simulation of solid-liquid turbulent flow in a stirred tank with a two-phase explicit algebraic stress model. Chemical Engineering Science 82, 272-284.

Fluent, A., 2011. Ansys Fluent Theory Guide. ANSYS Inc., USA.

Garcia-Ochoa, F., Gomez, E., 2004. Theoretical prediction of gas-liquid mass transfer coefficient, specific area and hold-up in sparged stirred tanks. Chemical Engineering Science 59, 2489-2501. 
Grenville, R.K., Nienow, A.W., 2004. Blending of miscible liquid. In Handbook of Industrial Mixing: Science and Practice,Paul, E.L., Atiemo-Obeng, V.A., Kresta, S.M. Eds.; John Wiley \& Sons: New York,Chapter9, pp.507-542.

Hanjalić, K., 1994. Advanced turbulence closure models: a view of current status and future prospects. International Journal of Heat and Fluid Flow 15, 178-203.

Hinze, J.O., 1959. Turbulence. McGraw-Hill: New York.

Jaworski, Z., Nienow, A., Dyster, K., 1996. An LDA study of the turbulent flow field in a baffled vessel agitated by an axial, down-pumping hydrofoil impeller. The Canadian Journal of Chemical Engineering 74, 3-15.

Kamil, M., Bushra, A., Ahmad, A., 2001. Minimum agitation speed for liquid-liquid-gas dispersion in mechanically agitated vessels. Chemical Engineering and Processing 40, 49-57.

Kasat, G., Khopkar, A., Ranade, V., Pandit, A., 2008. CFD simulation of liquid-phase mixing in solid-liquid stirred reactor. Chemical Engineering Science 63, 3877-3885.

Kataoka, I., Besnard, D., Serizawa, A., 1992. Basic equation of turbulence and modeling of interfacial transfer terms in gas-liquid two-phase flow. Chemical Engineering Communications 118, 221-236.

Khopkar, A., Rammohan, A., Ranade, V., Dudukovic, M., 2005. Gas-liquid flow generated by a Rushton turbine in stirred vessel: CARPT/CT measurements and CFD simulations. Chemical Engineering Science 60, 2215-2229.

Lane, G., Schwarz, M., Evans, G., 2000. Modelling of the interaction between gas and liquid in stirred vessels. Proceedings of the $10^{\text {th }}$ European Conference on Mixing, 197-204.

Launder, B., Reece, G.J., Rodi, W., 1975. Progress in the development of a 
Reynolds-stress turbulence closure. Journal of Fluid Mechanics 68, 537-566.

Launder, B.E., 1990. Phenomenological modelling: Present...and future?, Whither Turbulence?Turbulence at the Crossroads. The Series Lecture Notes in Physics $357,439-485$.

Launder, B.E., Spalding, D., 1974. The numerical computation of turbulent flows. Computer Methods in Applied Mechanics and Engineering 3, 269-289.

Launder, B.E., Spalding, D.B., 1972. Lectures in mathematical models of turbulence. Academic Press: London.

Laurenzi F., Coroneo M., Montante G., Paglianti A., Magelli F., 2009. Experimental and computational analysis of immiscible liquid-liquid dispersions in stirred vessels. Chemical Engineering Research and Design 87, 507-514.

Lien, F.-S., Leschziner, M., 1994. Assessment of turbulence-transport models including non-linear RNG eddy-viscosity formulation and second-moment closure for flow over a backward-facing step. Computers \& Fluids 23, 983-1004.

Linek, V., Benes, P., 1976. A study of the mechanism of gas absorption into oil-water emulsions. Chemical Engineering Science 31, 1037-1046.

Mlynek, Y., Resnick, W., 1972. Drop sizes in an agitated liquid - liquid system. AIChE Journal 18, 122-127.

Murthy, B., Ghadge, R., Joshi, J., 2007. CFD simulations of gas-liquid-solid stirred reactor: Prediction of critical impeller speed for solid suspension. Chemical Engineering Science 62, 7184-7195.

Murthy, B., Kasundra, R., Joshi, J., 2008. Hollow self-inducing impellers for gas-liquid-solid dispersion:Experimental and computational study. Chemical Engineering Journal 141, 332-345.

Nere, N., Patwardhan, A., Joshi, J., 2003. Liquid-phase mixing in stirred vessels: 
Turbulent flow regime. Industrial \& Engineering Chemistry Research 42, 2661-2698.

Nienow, A., 1990. Agitators for mycelial fermentations. Trends in Biotechnology 8, 224-233.

Nienow, A., 1997. On impeller circulation and mixing effectiveness in the turbulent flow regime. Chemical Engineering Science 52, 2557-2565.

Nygren, A., 2014. Simulation of bubbly flow in a flat bubble column. Master Thesis, Lund university, Sweden.

Open, C.F.D., 2011a. OpenFOAM programmer's guide, OpenFOAM Foundation.

Open, C.F.D., 2011b. OpenFOAM user guide, OpenFOAM Foundation.

Panneerselvam, R., Savithri, S., Surender, G.D., 2008a. CFD modeling of gas-liquid-solid mechanically agitated contactor. Chemical Engineering Research and Design 86, 1331-1344.

Panneerselvam, R., Savithri, S., Surender, G.D., 2008b. Computational Fluid Dynamics Simulation of Solid Suspension in a Gas-Liquid-Solid Mechanically Agitated Contactor. Industrial \& Engineering Chemistry Research 48, 1608-1620.

Parthasarathy, R., Jameson, G., Ahmed, N., 1991. Bubble breakup in stirred vessels: Predicting the Sauter mean diameter. Chemical Engineering Research \&Design 69, 295-301.

Peters, D.C., 1997. Dynamics of emulsification. In Mixing in the process industries,Harnby, N., Edwards, M.F., Nienow, A.W. Eds.; Butterworth-Heinemann's: Oxford, $2^{\text {nd }}$ ed., pp.294-321.

Ranade, V.V., 2002. Computational flow modeling for chemical reactor engineering. Academic Press: New York. 
Revill, B., 1982. Pumping capacity of disc turbine agitators - a literature review. Proceedings of the $4^{\text {th }}$ European Conference on Mixing,11-24.

Reynolds, W., 1987. Fundamentals of turbulence for turbulence modeling and simulation.Lecture Notes for Von Karman Institute, Agard Report No 755.

Rusche, H., 2003. Computational fluid dynamics of dispersed two-phase flows at high phase fractions. PhD Thesis, Imperial College London, Uk.

Saad, Y., 2003. Iterative methods for sparse linear systems. SIAM: Philadelphia.

Sato, Y., Sekoguchi, K., 1975. Liquid velocity distribution in two-phase bubble flow. International Journal of Multiphase Flow 2, 79-95.

Scargiali, F., D’Orazio, A., Grisafi, F., Brucato, A., 2007. Modelling and simulation of gas-liquid hydrodynamics in mechanically stirred tanks. Chemical Engineering Research and Design 85, 637-646.

Shan, X.G., Yu, G.Z., Yang, C., Mao, Z.-S., Zhang, W.G., 2008. Numerical simulation of liquid-solid flow in an unbaffled stirred tank with a pitched-blade turbine downflow. Industrial and Engineering Chemistry Research 47, 2926-2940.

Simonin, C., Viollet, P., 1990. Predictions of an oxygen droplet pulverization in a compressible subsonic coflowing hydrogen flow. Numerical Methods for Multiphase Flows91, 65-82.

Strek, F., 1977. Mixing and mixing equipment, SNTL: Prague.

Sun, H.Y., Mao, Z.-S., Yu, G.Z., 2006. Experimental and numerical study of gas hold-up in surface aerated stirred tanks. Chemical Engineering Science 61, 4098-4110.

Svensson, F., Rasmuson, A., 2006. PIV measurements in a liquid liquid system at volume percentages up to $10 \%$ dispersed phase. Experiments in Fluids 41, 917-931. 
Svensson, F.J.E., Rasmuson, A., 2004. LDA measurements in a stirred tank with a liquidliquid system at high volume percentage dispersed phase. Chemical Engineering \& Technology 27, 335-339.

van de Vusse, J.G., 1955. Mixing by agitation of miscible liquids Part I. Chemical Engineering Science 4, 178-200.

Van Ede, C., Van Houten, R., Beenackers, A., 1995. Enhancement of gas to water mass transfer rates by a dispersed organic phase. Chemical Engineering Science 50, 2911-2922.

van Heuven,J.W., Beek,W.J., 1970. Power input, drop size and minimum stirrer speed for liquid-liquid dispersions in stirred tanks. Proceedings of International Solvent Extraction Conference 51,70-81.

Wang, F., Mao, Z.-S., 2005. Numerical and experimental investigation of liquid-liquid two-phase flow in stirred tanks. Industrial \& Engineering Chemistry Research 44, $5776-5787$.

Wang, F., Mao, Z.-S., Wang, Y.F., Yang, C., 2006a. Measurement of phase holdups in liquid-liquid-solid three-phase stirred tanks and CFD simulation. Chemical Engineering Science 61, 7535-7550.

Wang, L., Zhang, Y., Li, X., Zhang, Y., 2010. Experimental investigation and CFD simulation of liquid-solid-solid dispersion in a stirred reactor. Chemical Engineering Science 65, 5559-5572.

Wang, W.J., Mao, Z.-S., Yang, C., 2006b. Experimental and numerical investigation on gas holdup and flooding in an aerated stirred tank with Rushton impeller. Industrial \& Engineering Chemistry Research 45, 1141-1151.

Yang, C., Bi, X.Y., Mao, Z.-S., 2002a. Effect of reaction engineering factors on biphasic hydroformylation of 1-dodecene catalyzed by water-soluble rhodium 
complex. Journal of Molecular Catalysis A: Chemical 187, 35-46.

Yang, C., Mao, Z.-S., Wang, Y.F., Chen, J.Y., 2002b. Kinetics of hydroformylation of propylene using $\mathrm{RhCl}(\mathrm{CO})(\mathrm{TPPTS}) 2 / \mathrm{TPPTS}$ complex catalyst in aqueous system. Catalysis Today 74, 111-119.

Yeoh, S., Papadakis, G., Yianneskis, M., 2004. Numerical simulation of turbulent flow characteristics in a stirred vessel using the LES and RANS approaches with the sliding/deforming mesh methodology. Chemical Engineering Research and Design 82, 834-848.

Zhang, Y.H., Yang, C., Mao, Z.-S., 2008. Large eddy simulation of the gas-liquid flow in a stirred tank. AIChE Journal 54, 1963-1974.

Zhao, Y.C., Li, X.Y., Cheng, J.C., Yang, C., Mao, Z.-S., 2011. Experimental study on liquid-liquid macro-mixing in a stirred tank. Industrial \& Engineering Chemistry Research 50, 5952-5958. 


\section{List of Tables and Figures}

Table 1. RSM model constants.

Table 2. Values of constants $A$ and $\chi$.

Table 3. Discretization schemes adopted in this work:

$\psi$ is a generic variable, $\nabla^{\perp}$ represents the normal gradient at cell surface, $(\ldots)_{f}$ stands for the operator of face interpolation (Open, 2011a, 2011b).

Table 4. Boundary conditions.

Table 5. Experimental conditions.

Table 6. Simulated flow data in single phase stirred tanks.

Table 7. Simulated flow data versus oil holdup ( $\left.N=425 \mathrm{rpm}, Q_{\mathrm{G}}=0.48 \mathrm{~L} / \mathrm{min}\right)$.

Table 8. Simulated flow data versus gas flow rate $\left(N=440 \mathrm{rpm}, \alpha_{\mathrm{o}, \mathrm{av}}=10 \%\right)$.

Figure 1. Experimental setup

1. injector, 2.stirred tank, 3. rotary torque transducer, 4.sparger, 5. conductivity electrode, 6. amplifier, 7. conductometer, 8.data collector, 9.computer.

Probe A: $115 \mathrm{~mm}$ from shaft axis and $192 \mathrm{~mm}$ from bottom;

Probe B: $115 \mathrm{~mm}$ from shaft axis and $30 \mathrm{~mm}$ from bottom.

Figure 2. Typical computational grid (cut mid-way between two baffles). 
Figure 3. Comparison of predicted mean velocities with experimental data $\left(N=540 \mathrm{rpm}, \quad \alpha_{\mathrm{o}, \mathrm{av}}=10 \%\right)$.

Figure 4. Comparison of predicted mean velocities with experimental data $\left(N=540 \mathrm{rpm}, \alpha_{\mathrm{o}, \mathrm{av}}=7 \%\right)$.

Figure 5. Comparison of predicted oil phase holdup profiles with experimental data $\left(N=400 \mathrm{rpm}, C=T / 2, \quad \alpha_{\mathrm{o}, \mathrm{av}}=10 \%\right)$.

Figure 6. Comparison of predicted oil phase holdup profiles with experimental data $\left(N=400 \mathrm{rpm}, C=T / 3, \quad \alpha_{\mathrm{o}, \mathrm{av}}=10 \%\right)$.

Figure 7. Predicted gas holdup contour map at a slice cut from mid-way between two baffles $\left(\alpha_{\mathrm{o}, \mathrm{av}}=1.0 \%, Q_{\mathrm{G}}=0.40 \mathrm{~L} / \mathrm{min}\right)$.

Figure 8. Predicted gas velocity vectors at a slice cut from mid-way between two baffles $\left(\alpha_{\mathrm{o}, \mathrm{av}}=1.0 \%, Q_{\mathrm{G}}=0.40 \mathrm{~L} / \mathrm{min}\right)$.

Figure 9. Predicted continuous phase velocity vectors at a slice cut from mid-way between two baffles $\left(\alpha_{\mathrm{o}, \mathrm{av}}=1.0 \%, Q_{\mathrm{G}}=0.40 \mathrm{~L} / \mathrm{min}\right)$.

Figure 10. Comparisons of simulated homogenization curves with experimental ones $\left(N=400 \mathrm{rpm}, \alpha_{\mathrm{o}, \mathrm{av}}=10 \%, Q_{\mathrm{G}}=0.32 \mathrm{~L} / \mathrm{min}\right)$

Figure 11. Mixing time versus oil holdup ( $N=425 \mathrm{rpm}, Q_{\mathrm{G}}=0.48 \mathrm{~L} / \mathrm{min}$ ).

Figure 12. Mixing time versus gas flow rate $\left(N=440 \mathrm{rpm}, \alpha_{\mathrm{o}, \mathrm{av}}=10 \%\right)$. 